\title{
LeAst-PRESENT-VALUE-OF-REVEnUe Auctions AND HIGHWAY FRANCHISING
}

\author{
By Eduardo M.R.A. Engel, Ronald D. Fischer and Alexander Galetovic ${ }^{1}$
}

This version: September, 2000

First version: July, 1998

\begin{abstract}
In recent years several countries have started massive highway franchising programs auctioned to private firms. In these auctions, the regulator typically sets the franchise term and firms bid on tolls or, alternatively, the regulator sets tolls and the winner is the firm that asks for the shortest franchise term. In both cases, the franchise term is fixed before the franchise begins. In this paper we propose a new auction mechanism, where the regulator sets the toll schedule and the firm that bids the least present value of toll revenue wins the franchise. With this scheme the franchise length adjusts endogenously to demand realizations.

Assuming that the regulator is not allowed to make transfers to the franchise holder, and that firms are unable to diversify risk completely, we characterize the full information optimal contract and show that it can be implemented with a Least-Present-Value-of-Revenue (LPVR) auction. Furthermore, for demand uncertainty and risk aversion parameters typical of developing countries, welfare gains associated with substituting an LPVR for a fixed-term auction are large (e.g., one third of the cost of the highway).
\end{abstract}

Keywords: Infrastructure franchising; Optimal contract; Optimal tolls; Ramsey pricing; Regulation; Risk; Self-financing constraint.

JEL classification: D81, H42, H54, L91.

\footnotetext{
${ }^{1}$ The authors are at the University of Chile; Engel is also with the NBER. Address: Center for Applied Economics (CEA), Department of Industrial Engineering, University of Chile, P.O.Box 2777, Santiago, Chile. E-mail: eengel@dii.uchile.cl, rfischer@dii.uchile.cl, agaleto@dii.uchile.cl. Financial support from Fondecyt (Grants 1980658 and 1981188); the Dirección de Investigación, Fac. Cs. Físicas y Matemáticas, University of Chile; and institutional grants to CEA from the Mellon and Hewlett Foundations are gratefully acknowledged. This paper benefited from comments by James Hines, Jean Tirole, an editor of this Journal, an anonymous referee and seminar participants and discussants at the Econometric Society Meetings in Seattle (2000) and Cancún (1999); the IEA Meeting in Buenos Aires (1999); LSE; MIT; Harvard, Hebrew and Stanford Universities; Universities of California (Santa Cruz), Chile, Michigan, Paris (CERAS), Pompeu Fabra and Toulouse.
} 
The greater part of public works may easily be so managed, as to afford a particular revenue sufficient for defraying their own expense, without bringing any burden upon the general revenue of society [...] When high roads [...] are in this manner made and supported by the commerce that is carried on by means of them, they can be made only where that commerce requires them. Their expence too, their grandeur and magnificence, must be suited to what that commerce can afford to pay. [...] A magnificent road cannot be made [...] merely because it happens to lead to the country villa of the intendant of the province, or to that of some great lord to whom the intendant finds it convenient to make his court.

Adam Smith, The Wealth of Nations, V.1.III.1

\section{Introduction}

There is widespread agreement that most developing countries urgently need massive highway construction programs. $^{2}$ Highways have traditionally been viewed as public goods that should be built, financed and operated by the public sector. However, in recent decades chronic budgetary problems have led governments to neglect the upkeep of existing roads while traffic has grown well ahead of their capacity. The task of rebuilding and making new roads is beyond the capabilities of most governments, so that it has become increasingly accepted that private firms should build, finance and operate highways, and that users should pay for their cost. ${ }^{3}$

In recent years many countries have started massive highway franchising programs via so-called buildoperate-and-transfer (BOT) contracts. ${ }^{4}$ Under such a contract, a private firm builds and finances the highway and then collects tolls for a long period, usually between 10 and 30 years. When the franchise ends the road reverts to the state.

The first franchises were usually conferred in bilateral negotiations, but increasingly, competitive auctions are being used to award them. Many highways are natural monopolies, ${ }^{5}$ and the premise that underlies the use of auctions is that they lead to efficient outcomes-competition for the field as a good substitute for competition in the field, an idea that goes back to Chadwick (1859) and was popularized by Demsetz (1968). Typically, the regulator fixes the franchise term, and the road is awarded to the firm that bids the lowest toll; alternatively, the regulator fixes the toll and the winner is the firm that bids the shortest franchise term. Both are fixed-term franchises, i.e. the franchise term is fixed before the franchise begins.

In this paper we show that fixed-term franchises can be improved upon significantly by allowing the franchise term to adjust with demand realizations. We first characterize the full-information optimal contract. This contract trades off optimally the distortions caused by tolls against the revenue uncertainty faced by the risk averse franchise holder. A key characteristic of this contract is that franchises last longer when

\footnotetext{
${ }^{2}$ See for example Irwin et al. (1997).

${ }^{3}$ According to The Economist, "As many countries have neither the finances nor the managerial resources for the task [...], private companies will have to do much of the job." (February 1, 1997, p. 63.)

${ }^{4}$ See Gómez-Ibáñez and Meyer (1993) for a thorough discussion of the international experience.

${ }^{5}$ Mexico was an interesting exception, where the franchised highways were built parallel to free (but congested) public highways. Perhaps coincidentally, most of these projects had to be rescued by the government.
} 
demand turns out to be low. We next show that the optimal contract can be implemented with a simple competitive auction, where firms bid on the present value of toll revenue they want to obtain over the lifetime of the franchise - a Least-Present-Value-of-Revenue (LPVR) auction. Finally, we develop a simple methodology to estimate the benefits from moving from fixed term to LPVR auctions. These calculations suggests that the gains are significant: approximately one-third of investment costs using parameter values typical for developing countries.

Highway franchises have several distinctive features. First, a large fraction of the costs of the franchise are sunk when the road is built and before demand becomes known; operating and maintenance costs are comparatively small and are therefore ignored. Second, in order to alleviate strained budgets, roads have to be financed by tolls on users. For this reason we introduce a 'self-financing constraint', which implies that tolls may have to be set above those that induce drivers to internalize congestion optimally (henceforth congestion tolls). Third, it has often been overlooked that medium- and long-term traffic forecasts are very imprecise. This leads to considerable demand uncertainty, most of it beyond the control of the franchise holder. ${ }^{6}$ Since it appears that firms are often unable to fully diversify idiosyncratic risks, we assume risk averse firms. ${ }^{7}$ As in principal-agent models, the less risk averse party —in our case the planner — is assumed to be risk neutral.

Our strategy is to characterize the full information optimal contract and then to show that it can be implemented with an LPVR auction. The intuition behind our main results is simplest in the case of a high-demand road, i.e., a road that can be financed in all states of the world charging the congestion toll. ${ }^{8}$ Then, the optimal contract is such that the firm collects tolls until the present value of revenue equals the up front investment. After this time, the road reverts to the state. Hence the firm bears no risk, congestion tolls are charged in all states of demand, the franchise lasts longer when demand is low, and the self-financing constraint is not binding.

This contract can be implemented via a simple auction where participants bid a sum representing the present value of toll revenues they would want, assuming that the government will set the congestion toll in each state of demand. The franchise lasts until the franchise holder collects its desired revenue and then reverts to the state, which continues to charge the congestion toll. If all bidders have the same technology, the winning bid equals the investment required to build the road and rents are dissipated by competition. Hence, the franchise term varies across states of demand while revenues collected by the firm remain constant in present value. This means that the auction replicates the full-information optimal contract.

Also note that in the high-demand case described above, an LPVR auction provides full insurance to

\footnotetext{
${ }^{6}$ For example, in the case of the privately owned Dulles Greenway toll road, joining Dulles Airport near Washington, D.C. to Leesburg, two independent traffic consultant companies predicted a daily flow of 35,000 vehicles for an average toll of $\$ 1.75$. Actual traffic turned out to be 8,500 .

${ }^{7}$ It is a well established fact that private firms and financiers usually refuse to participate unless governments pledge guarantees against commercial risks. If project related risks could be diversified, there would be no demand for guarantees. See Irwin et al. (1997) for an extensive discussion of government guarantees in private infrastructure projects and Appendix D in Engel, Fischer and Galetovic - henceforth EFG_ (1998) for an example where agency problems prevent an entrepreneur from diversifying risks.

${ }^{8}$ Recall that the congestion toll is the toll that induces drivers to internalize congestion optimally in the absence of a self-financing constraint.
} 
the franchise holder and there are no toll-induced distortions. By contrast, in the standard infrastructure auction where the franchise is awarded on the basis of the minimum toll for a fixed term, the franchise holder receives different amounts of revenue in different states of the world. A risk averse franchise holder will require an additional return in order to bear this risk, leading to a suboptimal outcome.

An LPVR auction is also optimal when the congestion toll is not sufficient to finance the road in all states of demand. To get the intuition in this case, assume that there is one (henceforth the low-demand) state where the present value of congestion toll revenues is insufficient to pay for the road even if the franchise were to last forever. An analogy to static Ramsey pricing suggests that the planner should set distortionary tolls not only in the low-demand state but also in the remaining (henceforth high-demand) states, in order to smooth income across demand realizations for a risk averse firm. In the present case however, the time dimension adds an additional degree of freedom since revenue in high-demand states can be raised by lengthening the franchise without introducing distorting tolls. This fact implies that the optimal contract has a simple structure.

First, in all high demand states, the present value of tolls collected by the franchise holder is the same, congestion tolls are charged, and franchise terms are finite. Second, it is optimal to distort tolls in the lowdemand state, since a small distortion leads to a first order welfare gain via risk reduction and only a second order welfare loss due to toll distortion. Third, since it is better to introduce small distortions for a long time than to introduce large distortions for short periods, in low demand states the franchise lasts forever. Last, revenue in each high-demand state is higher than in the low-demand state (and also higher than investment), and the franchise holder bears some risk.

The characteristics described above enable the planner to implement the optimal contract with an LPVR auction. First, the winning bid will equal the present value of revenue common to all high-demand states. Second, the winning bid provides the planner with the information necessary to set the tolls from the optimal contract both in high- and low-demand states. Third, in a high-demand state the franchise lasts until revenues equal to the winning bid are collected; in low-demand states it lasts forever.

An LPVR auction exploits the fact that the present value of revenue is the only one-dimensional bidding variable that enables the regulator to implement the optimal contract. By contrast, if firms bid on the toll, the resulting contract will have a toll that is constant across states of demand and therefore cannot be optimal. Alternatively, if the regulator sets state-contingent tolls and firms compete on the shortest franchise term, the resulting contract cannot be optimal either since its length does not vary with demand realizations.

In order to implement the contract described above, the planner must be able to resist the temptation to help the franchise holder in those states of demand where it makes losses. For this reason we call this contract the optimal commitment contract. Experience suggests that contracts are often renegotiated when demand turns out to be lower than expected. ${ }^{9}$ For this reason we also study the case where the planner sets

\footnotetext{
${ }^{9}$ For example, in Spain, 12 concessions were awarded before 1973. In several of these, building costs were 4 to 5 times higher than projected, and traffic was about one-third of original projections. As a result, three firms went bankrupt, two were absorbed by stronger franchise holders, and toll increases and term extensions were granted by the government; see Gómez-Ibáñez and Meyer (1993, chs. 8, 9 and 10). As another example, Mexico franchised the construction and operation of more than 3,000 miles of
} 
tolls that guarantee the franchise holder a normal return in all states of demand, i.e., it provides full insurance. We call this contract the optimal no-commitment contract. We derive the optimal full-information contract, show that it can also be implemented with an LPVR auction and that it differs from fixed term contracts.

The planner's problem can be viewed as an extension of the standard Ramsey problem where the length of a franchise is an additional choice variable. This paper is also related to the literature on franchise bidding pioneered by Chadwick (1859) and Demsetz (1968) (see also Stigler [1968], Posner [1972] and Riordan and Sappington [1987]). ${ }^{10}$ Following this literature, we show how competition for the franchise can be used to regulate a monopoly. Our contribution is to study how demand risk affects the optimal contract, considering explicitly the intertemporal nature of franchise contracts. Finally, this paper is also related to the literature on the optimal regulation of natural monopolies (see, for example, Laffont and Tirole [1993]).

The rest of the paper is organized as follows. In Section 2 we present the model and the planner's problem. The latter is solved in Section 3. In Section 4 we show that an LPVR auction implements the social optimum. Moreover, we show that a fixed-term auction generically cannot implement the optimum. In Section 5 we make a quantitative comparison between LPVR and fixed-term auctions. Section 6 concludes and discusses extensions. An appendix follows.

\section{The model and the planner's problem}

A benevolent social planner wants to hire a private firm to build a highway whose technical characteristics are exogenous. ${ }^{11}$ The firm can only be compensated with toll revenues, as we assume that other sorts of compensation, such as monetary transfers from the planner to the firm, are not allowed. The planner's objective is to maximize the expected present value of driver welfare subject to finding a firm willing to build the road. ${ }^{12}$ The road is franchised for a period during which the franchise holder collects tolls. When the franchise ends the road reverts to the state and any future tolls are returned to drivers lump-sum.

There are $n$ possible states of demand. In state $i$, which occurs with probability $\pi_{i}>0$, the marginal benefit of an additional trip when $Q$ trips are made is $B_{i}(Q)$. We assume that the state of demand becomes known immediately after the road is built, so that demand remains constant through time. The toll charged for using the road in state $i$ is $P_{i} \geq 0$, and the time-cost of using the road when $Q$ vehicles are on it is $c(Q)$, which is independent of the state. Then $P+c(Q)$ is the generalized travel cost, and the number of cars on the road in state $i$ is determined by

highways in the late 1980's and early 1990's. Virtually all concessions were renegotiated after cost overruns and low revenues, with a (declared) cost to the government of US\$6 billion. This amount does not include the cost to users due to term extensions, since in several cases the terms more than doubled (see El Mercurio, June 17, 1996, p. A8, "Apertura Vial Lleva a Desastre Económico," an article reproduced from the Los Angeles Times, and the article in the Mexican weekly Proceso of February 12, 1996).

${ }^{10}$ But see Williamson $(1976,1985)$ for a critique.

${ }^{11}$ Thus, in this paper we do not study the problem of choosing the optimal scale and timing of the project.

${ }^{12}$ This objective function assumes that the income of users is uncorrelated with the benefit of using the road, so that if users spend a small fraction of their incomes on tolls they will value the benefits produced by the road as if they were risk neutral. See Arrow and Lind (1970). 


$$
B_{i}\left(Q_{i}\right)=P_{i}+c\left(Q_{i}\right) .
$$

We impose some technical restrictions on the marginal benefit and cost functions:

$$
\begin{gathered}
B_{i}(q)>0, B_{i}^{\prime}(q)<0 \text { and } B_{i}^{\prime \prime}(q) \leq 0 ; \text { for } 0 \leq q<\bar{q}_{i} \text {, with } B_{i}\left(\bar{q}_{i}\right)=0 \text { and } B_{i}(0)>c(0) \\
c, c^{\prime} c^{\prime \prime} \geq 0 .
\end{gathered}
$$

That is, in all states the marginal benefit function is strictly positive, strictly decreasing and concave and the time-cost function is increasing and convex in the number of drivers on the road. ${ }^{13}$

It will be useful to work with a demand function $Q_{i}(P)$ that is determined from the equilibrium condition (1). It is straighforward to show that this demand function is well defined, concave and strictly decreasing (that is, $Q_{i}^{\prime}(P)<0, Q_{i}^{\prime \prime}(P) \leq 0$ ). Moreover, the demand elasticity $\eta_{i}(P)$ is strictly decreasing with $\eta_{i}(0)=0$ and $\eta_{i}\left(P_{i}^{M}\right)=-1$, where $P_{i}^{M}$ is the monopoly toll in state $i .^{14}$

In state $i$ consumer surplus is given by

$$
C S_{i}(P) \equiv \int_{0}^{Q_{i}(P)} B_{i}(q) d q-Q_{i}(P)\left[P+c\left(Q_{i}(P)\right)\right]
$$

which, given assumptions (2) and (3), is finite. Since tolls paid by drivers redistribute income between drivers and the franchise holder, the net instantaneous social surplus is

$$
G_{i}(P) \equiv C S_{i}(P)+P Q_{i}(P)
$$

The function $G_{i}$ is strictly concave by conditions (2) and (3). ${ }^{15}$ It follows that when congestion costs are unimportant $G_{i}(P)$ is decreasing for all $P$, and therefore attains its maximum at $P_{i}^{*}=0$. On the other hand, when congestion costs are considerable, $G_{i}(P)$ has a unique interior maximum at $P_{i}^{*}>0$. It is evident that when $P_{i}=P_{i}^{*}$, users internalize the congestion externality they create. ${ }^{16}$ Thus, we denote by $P_{i}^{*}$ the congestion toll in state $i$.

For each possible state of demand the planner chooses two tolls, the one that users pay to the franchise holder during the life of the franchise and a second toll that is collected by the planner after the end of the franchise. The revenue from the latter is returned to users as a lump-sum. The tolls in state $i$ are denoted by $P_{i}^{F}$ and $P_{i}^{A}$, where the superscripts " $F$ " and " $A$ " stand for franchise and after, respectively. The length of the franchise in state $i$ is denoted by $T_{i}$.

Since we are not interested in construction cost uncertainty, we assume that there are many identical firms that can build the highway at cost $I>0$. There are no maintenance costs and the road does not de-

\footnotetext{
${ }^{13}$ Thus, we are assuming that there is no hypercongestion.

${ }^{14}$ For proofs of these results see Appendix A in EFG (1998).

${ }^{15}$ See Appendix A in EFG (1998).

${ }^{16}$ Lemma A.3 in EFG (1998) provides a proof.
} 
preciate. ${ }^{17}$ Firms are risk-averse expected-utility maximizers, with twice-continuously differentiable utility functions $u$ defined over net revenue $\mathrm{PVR}_{i}-I$, where

$$
\mathrm{PVR}_{i} \equiv \int_{0}^{T_{i}} P_{i}^{F} Q_{i}\left(P_{i}^{F}\right) e^{-r t} d t
$$

is the present value of the franchise holder's income in demand state $i$, discounted at the risk-free interest rate, $r$. Each firm has an outside option that yields utility $u(0)$.

We assume that a dollar in the hands of users is socially more valuable than in the pocket of the franchise holder (as in Laffont and Tirole [1993]). ${ }^{18}$ Given this assumption, it is easy to show that there is no loss of generality in assuming that the objective function of the planner does not include the rents accruing to the franchise holder. ${ }^{19}$ Thus, the planner wants to extract all rents from the franchise holder and the firm's participation constraint holds with equality:

$$
E u\left(\mathrm{PVR}_{i}-I\right)=u(0)
$$

Since the planner returns the revenue he receives after the franchise ends to users, as a lump sum, his payoff in state $i$ may be written as:

$$
W_{i}\left(P_{i}^{F}, P_{i}^{A}, T_{i}\right) \equiv \int_{0}^{T_{i}} C S_{i}\left(P_{i}^{F}\right) e^{-r t} d t+\int_{T_{i}}^{\infty} C S_{i}\left(P_{i}^{A}\right) e^{-r t} d t+\int_{T_{i}}^{\infty} P_{i}^{A} Q_{i}\left(P_{i}^{A}\right) e^{-r t} d t,
$$

which after some rewriting, and defining $L_{i} \equiv e^{-r T_{i}}$, is equal to

$$
\frac{G_{i}\left(P_{i}^{F}\right)}{r}\left(1-L_{i}\right)+\frac{G_{i}\left(P_{i}^{A}\right)}{r} L_{i}-\mathrm{PVR}_{i}
$$

The planner chooses a toll and franchise-period schedule $\left(P_{i}^{F}, P_{i}^{A}, L_{i}\right)_{i=1}^{n}$ to maximize the expected value of (7) subject to the firm's participation constraint (6). ${ }^{20}$

If the planner could make monetary transfers to the franchise holder, she would choose $P_{i}^{F}$ and $P_{i}^{A}$ equal to the congestion toll $P_{i}^{*}{ }^{21}$ Since the participation constraint is no longer relevant at the end of the franchise, the planner always sets $P_{i}^{A}=P_{i}^{*}$. Nevertheless, in order to raise revenue and satisfy the participation constraint, the planner may need to distort tolls during the franchise. The optimal toll in state $i$

\footnotetext{
${ }^{17}$ With a minor change in notation all results in this paper can be shown to hold when maintenance costs are proportional to the number of vehicles using the road. The engineering literature on this issue suggests that, except for low quality roads, deterioration depends mainly on use, not time. See Small et al. (1989).

${ }^{18}$ One justification could be social preferences on the distribution of income; another that, particularly in developing countries, many foreign firms participate in the highway business.

${ }^{19}$ In fact, LPVR is still optimal when franchise rents are as valuable as consumer surplus.

${ }^{20}$ The objective function (7) assumes a benevolent planner, which may be somewhat contradictory with forcing a self-financing constraint—a benevolent planner should be given free hand to use subsidies to maximize welfare. We follow the regulation literature in studying the normative Ramsey-Boiteaux problem given the self-financing constraint. See also the discussion in Laffont and Tirole (1993, ch. 3.4).

${ }^{21}$ As taxes are usually distortionary, actually the optimal toll should be slightly above the congestion toll.
} 
during the franchise, which we denote by $P_{i}^{O},{ }^{22}$ satisfies

$$
P_{i}^{*} \leq P_{i}^{O} \leq P_{i}^{M}
$$

That is, the optimal toll lies between the congestion toll and the monopoly toll. ${ }^{23}$ In the remainder of the paper, the following definitions and notation will be useful. First, if

$$
\frac{P_{i} Q_{i}\left(P_{i}\right)}{r} \geq I
$$

then we say that the road is self-financing in state $i$ charging toll $P_{i}$. Second

$$
\mathrm{PVR}_{i}^{*} \equiv \frac{P_{i}^{*} Q_{i}\left(P_{i}^{*}\right)}{r}
$$

is the present value of revenue collected if the franchise lasts forever and the toll equals the congestion toll. Analogously, define $\mathrm{PVR}_{i}^{M}$ by substituting $P_{i}^{M}$ for $P_{i}^{*}$ in (9). Finally,

$$
\operatorname{PVR}_{i}^{O} \equiv \frac{P_{i}^{O} Q_{i}\left(P_{i}^{O}\right)}{r}\left(1-L_{i}^{O}\right)
$$

is the present value of revenue collected by the franchise holder if tolls and franchise terms are chosen optimally. ${ }^{24}$ Now we can study the planner's problem.

\section{The planner's solution}

In this section we find the contract that solves the planner's problem, and develop a simple classification of roads based on this contract.

\subsection{The commitment case}

Most highway franchises have been awarded under a contract that fixes a state-independent toll and franchise term before the road is built; that is for all $i, j, P_{i}^{F}=P_{j}^{F}=P$ and $T_{i}=T_{j}=T$. In such fixed-term contracts the government has committed in principle (though often not in practice) to change neither tolls nor the franchise period. This is a special case of a more general contract where the planner commits to a toll and franchise-term schedule $\left(P_{i}^{F}, P_{i}^{A}, L_{i}\right)_{i=1}^{n}$ before the realization of demand. In this subsection we characterize the optimal contract within this class.

\footnotetext{
${ }^{22}$ Henceforth the superscript " $O$ " will denote the optimal value of a variable during the franchise period.

${ }^{23}$ To rule out $P_{i}^{O}<P_{i}^{*}$, note that raising $P_{i}^{O}$ increases welfare (since $G_{i}$ is concave and attains its maximum at $P_{i}^{*}$ ) and increases revenue (since demand is relatively inelastic). A similar argument rules out $P_{i}^{O}>P_{i}^{M}$.

${ }^{24}$ Recall that $L_{i}^{O}=e^{-r T_{i}^{O}}$, where $T_{i}^{O}$ is the optimal franchise term in state $i$.
} 
From (7) we have that the planner solves

$$
\max _{\left(P_{i}^{F}, P_{i}^{A}, L_{i}\right)_{i=1}^{n}} \sum_{i} \pi_{i}\left[\frac{G_{i}\left(P_{i}^{F}\right)}{r}\left(1-L_{i}\right)+\frac{G_{i}\left(P_{i}^{A}\right)}{r} L_{i}-\mathrm{PVR}_{i}\right]
$$

subject to the firm's participation constraint (6). Suppose that $\sum_{i} \pi_{i} u\left(\mathrm{PVR}_{i}^{M}-I\right) \geq u(0)$, that is, that the road is self-financing under monopoly tolls. Then there exists a solution for this problem. ${ }^{25}$ The assumption of commitment implies that the planner can compel the franchise holder to accept losses in some states, and guarantee to compensate him with profits in other states; that is, $u\left(\mathrm{PVR}_{i}-I\right)=u(0)$ need only hold on average, not in every state of demand. Commitment gives the planner the possibility of distorting less in low-demand states and compensating the franchise holder with a longer franchise in high-demand states, thereby trading off user distortions against the risk borne by the franchise holder.

The planner's problem may be viewed as a Ramsey pricing problem. The state-contingent tolls can be viewed as the prices of the different goods while the firm's participation constraint corresponds to the budget constraint. Two aspects of our problem differ from standard Ramsey problems. First, the firm is risk averse with respect to income. Second, and more important, the planner has twice as many instruments at his disposal: she can set a toll and also choose the franchise length for each state of demand. As we show shortly, it is the possibility of exploiting the time dimension that underlies the main results in this paper.

We start with an important lemma that characterizes the trade-off between toll distortions and risk forced on the franchise holder.

Lemma 3.1 (a) For all states $i, P_{i}^{O}>0$, and $T_{i}^{O}>0$ (i.e., $L_{i}^{O}<1$ ).

(b) The following term is independent of the state $i$ :

$$
\frac{Q_{i}\left(P_{i}^{O}\right)\left[1+\eta_{i}\left(P_{i}^{O}\right)\right]}{Q_{i}\left(P_{i}^{O}\right)\left[1+\eta_{i}\left(P_{i}^{O}\right)\right]-G_{i}^{\prime}\left(P_{i}^{O}\right)} u_{i}^{\prime} \equiv u^{\prime}
$$

Proof See Theorem 7.1 in the appendix.

Part (a) of the lemma says that the franchise holder receives positive revenues in all states. Part (b) summarizes the insurance-distortion tradeoff. In the planner's solution, the term in (11) is smaller in those states in which the firm's revenue is larger (since the expression is increasing in $u^{\prime}$, which is decreasing in revenue) and when tolls are higher (as reflected both by $\eta_{i}\left(P_{i}^{O}\right)$ and $G_{i}^{\prime}\left(P_{i}^{O}\right)$, both of which have an absolute value that increases with $P_{i}^{O}$ ).

Even though (11) characterizes the solution in the commitment case, it does not provide much intuition on the form of the optimal franchise contract, nor does it suggest how to design an auction that implements the planner's solution. For this reason we use (11) to derive a series of propositions that provide a simple

\footnotetext{
${ }^{25}$ See Proposition 7.1 in the Appendix for a proof.
} 
description of the optimal contract and that serve as a basis to derive its implementation via a competitive auction. The first proposition shows that if the road is self financing charging congestion tolls in all states of demand $\left(\mathrm{PVR}_{i}^{*} \geq I\right.$ for all $\left.i\right)$ then the optimal contract sets the congestion toll in all states, the participation constraint holds in every state of demand and the franchise holder receives full insurance. ${ }^{26}$

Proposition 3.1 (Full insurance) Let $\mathrm{PVR}_{i}^{*} \geq I$ for all $i$. Then the optimal franchise contract is such that for all states $i, P_{i}^{F}=P_{i}^{*}$ and $\mathrm{PVR}_{i}^{O}=I$.

Proof Since $\mathrm{PVR}_{i}^{*} \geq I$, the solution is feasible and meets the participation constraint. If $P_{i}^{F}=P_{i}^{*}$ then $G_{i}^{\prime}\left(P_{i}^{*}\right)=0$, and from Lemma 3.1 we have that $u_{i}^{\prime}=u_{j}^{\prime}$ for all $i, j$, so that $\mathrm{PVR}_{i}^{O}=\mathrm{PVR}_{j}^{O}$. Finally, $\mathrm{PVR}_{i}^{O}=I$ minimizes the transfer to the franchise holder.

The intuition behind this proposition is quite straightforward. First, if the road is self-financing when the congestion toll is charged in all states of demand, there is no need to distort in order to satisfy the participation constraint. Second, since the franchise holder is risk-averse, the transfer is minimized when he is given full insurance. Last, since in general $\mathrm{PVR}_{i}^{*} \neq \mathrm{PVR}_{j}^{*}$, the franchise term is variable: the franchise lasts longer when demand is low.

Proposition 3.1 is not general, because nothing ensures that $\mathrm{PVR}_{i}^{*} \geq I$ for all $i$. For roads such that $\mathrm{PVR}_{i}^{*}<I$ in at least some state $i$, the planner must trade off the benefit of insuring the franchise holder (i.e., that reduced risk implies a smaller transfer to the franchise holder) against the costs of raising tolls and creating a distortion. In what follows we characterize this tradeoff.

When $\mathrm{PVR}_{i}^{*}<I$ in at least some state $i$, states of demand can be classified in two categories: those where the planner sets congestion tolls and those where the planner, optimally, chooses to distort tolls by setting $P_{i}^{F}>P_{i}^{*}$. We begin by studying tolls in a state $i$ where the planner optimally sets $P_{i}^{F}>P_{i}^{*}$. Suppose that, for the optimal contract, the franchise holder's revenue in state $i$ is $\mathrm{PVR}_{i}^{O}$. In principle the planner faces the following tradeoff: given $\mathrm{PVR}_{i}^{O}$, a lower toll means a smaller instantaneous distortion, but for a longer term. The next proposition shows that the concavity of $G_{i}$ implies that the planner has a preference for toll smoothing, so that it is optimal to charge forever the lowest possible toll consistent with $\mathrm{PVR}_{i}=\mathrm{PVR}_{i}^{O}$.

Proposition 3.2 (Toll smoothing) For all states $i$ such that $P_{i}^{O}>P^{*}, T_{i}^{O}=\infty$.

Proof Given the concavity of $G_{i}$, the proof is similar to that of standard insurance results, see EFG (1998) for details.

Next we characterize revenues in those states where congestion tolls are charged.

Proposition 3.3 For all states $i, j$ such that $P_{i}^{O}=P_{i}^{*}$ and $P_{j}^{O}=P_{j}^{*}, \mathrm{PVR}_{i}^{O}=\mathrm{PVR}_{j}^{O}$.

\footnotetext{
${ }^{26}$ In EFG (1997a) we prove this result assuming perfectly inelastic demands, no congestion and no demand-contingent tolls.
} 
Proof Note that $G_{i}^{\prime}\left(P_{i}^{*}\right)=G_{j}^{\prime}\left(P_{j}^{*}\right)=0$. From Lemma 3.1, $u_{i}^{\prime}=u_{j}^{\prime}$; hence $\operatorname{PVR}_{i}^{O}=\operatorname{PVR}_{j}^{O}$.

The intuition behind this result is quite simple, at least in the case where the optimal franchise length in both states is finite. Consider two states $i, j$ where $P_{i}^{O}=P_{i}^{*}$ and $P_{j}^{O}=P_{j}^{*}$, but where $\mathrm{PVR}_{i}^{O}<\mathrm{PVR}_{j}^{O}$. Then if we extend the franchise a bit in state $i$ and shorten it in state $j$ so that expected revenue does not change, the planner's objective function does not change and the firm's participation constraint becomes slack. Hence, the franchise terms in $i$ and $j$ were suboptimal.

The next proposition shows that the franchise holder will collect more revenue in states where congestion tolls are charged than in states with distortionary tolls.

Proposition 3.4 For all states $i$, $j$ such that $P_{i}^{O}>P_{i}^{*}$ and $P_{j}^{O}=P_{j}^{*}, \mathrm{PVR}_{i}^{O}<\mathrm{PVR}_{j}^{O}$.

Proof Suppose that $P_{i}^{O}>P_{i}^{*}$ and $P_{j}^{O}=P_{j}^{*}$. Since $G_{i}^{\prime}\left(P_{i}^{*}\right)=0$, by Lemma 3.1 we have that

$$
\frac{Q_{i}\left(P_{i}^{O}\right)\left[1+\eta_{i}\left(P_{i}^{O}\right)\right]}{Q_{i}\left(P_{i}^{O}\right)\left[1+\eta_{i}\left(P_{i}^{O}\right)\right]-G_{i}^{\prime}\left(P_{i}^{O}\right)} u_{i}^{\prime}=u_{j}^{\prime} .
$$

Since $G_{i}^{\prime}\left(P_{i}^{O}\right)<0$ and $\eta_{i}\left(P_{i}^{O}\right) \geq-1$, the fraction on the LHS is smaller than one. Thus $u_{i}^{\prime}>u_{j}^{\prime}$ and hence, by concavity of $u, \operatorname{PVR}_{i}^{O}<\operatorname{PVR}_{j}^{O}$.

Note that Propositions 3.3 and 3.4 imply that if there exists at least one state where optimal tolls are distortionary, then in those states where congestion tolls are charged we have $\mathrm{PVR}^{O}>I$, that is, the franchise holder makes a profit. It follows that if $\mathrm{PVR}_{i}^{*}<I$ then $P_{i}^{O}>P_{i}^{*} \cdot{ }^{27}$ Moreover, since the participation constraint must bind, the franchise holder must lose money in some states.

To conclude we show that if in a given state it is optimal to charge the congestion toll, then in all states with higher PVR* it is also optimal to charge the corresponding congestion toll.

Proposition 3.5 If $\mathrm{PVR}_{i}^{*} \leq \mathrm{PVR}_{j}^{*}$ and $P_{i}^{O}=P_{i}^{*}$, then $P_{j}^{O}=P_{j}^{*}$.

Proof See Appendix A in EFG (1998).

Proposition 3.5 allows us to order states of demand in a simple way. Without loss of generality, assume that $\mathrm{PVR}_{1}^{*} \leq \mathrm{PVR}_{2}^{*} \leq \ldots \leq \mathrm{PVR}_{n}^{*}$ (we will keep this convention in the rest of the paper). It follows that if $P_{i}^{O}=P_{i}^{*}$, then $P_{i+1}^{O}=P_{i+1}^{*}, \ldots, P_{n}^{O}=P_{n}^{*}$. Conversely, if $P_{i}^{O}>P_{i}^{*}$, then $P_{i-1}^{O}>P_{i-1}^{*}, \ldots, P_{1}^{O}>P_{1}^{*}$.

To summarize, the preceding results show that when the planner can commit, the structure of the optimal contract $\left(P_{i}^{O}, L_{i}\right)_{i=1}^{n}$, is quite simple. First, either tolls are distorted and the franchise lasts forever, or congestion tolls are set and the franchise lasts until a given PVR is collected (Propositions 3.2 and 3.3). Second, the revenues of the franchise holder are higher in those states where congestion tolls are optimal (Proposition 3.4). Finally, if it is optimal to charge the congestion toll in a particular state of demand $i$ then

\footnotetext{
${ }^{27}$ The converse is not true: if $\mathrm{PVR}_{i}^{*} \geq I$, it does not follow that $P_{i}^{O}=P_{i}^{*}$.
} 
it is optimal to set congestion tolls in all states $j$ that collect at least as much revenue as $i$ when congestion tolls are set (Proposition 3.5).

\subsection{The no-commitment case}

As mentioned in the introduction, in the real world it is common for franchise contracts to be renegotiated in those states of demand where the franchise holder loses money under the original contract. ${ }^{28}$ For political economy reasons, once it becomes apparent that the franchise holder will suffer losses, governments seem unable to resist pressures to renegotiate. Since the franchise holder will lose money in those states of demand $i$ such that $\mathrm{PVR}_{i}^{*}<I$, it follows that in many cases it may be unrealistic to expect governments to implement the optimal contract. However, as in the case of utilities, the government may be able to precommit to allow the franchise holder a normal rate of return in every state of demand: that is, after the road is built, for all states $i$ she will set tolls such that $P_{i} Q_{i}\left(P_{i}\right)=r I$. In that case, for all $i$ the planner solves

$$
\max _{P_{i}^{F}, P_{i}^{A}, L_{i}} \frac{G_{i}\left(P_{i}^{F}\right)}{r}\left(1-L_{i}\right)+\frac{G_{i}\left(P_{i}^{A}\right)}{r} L_{i}-\mathrm{PVR}_{i}
$$

subject to $\mathrm{PVR}_{i}=I$.

The following proposition characterizes the optimum.

Proposition 3.6 Assume that for all states $i: \mathrm{PVR}_{i}^{M} \geq I$. Then:

(a) if $\mathrm{PVR}_{i}^{*} \geq I$, then $P_{i}^{F}=P_{i}^{A}=P_{i}^{*}$, and $T_{i}$ is set so as to satisfy $\mathrm{PVR}_{i}=I$;

(b) if $\mathrm{PVR}_{i}^{*}<I$, then $T_{i}=\infty$ and the optimal toll is determined by

$$
\frac{P_{i}^{O} Q_{i}\left(P_{i}^{O}\right)}{r}=I
$$

Proof In case (a), the maximum is attained at $P_{i}^{F}=P_{i}^{A}=P_{i}^{*}$ and the self-financing constraint determines the franchise length $T_{i}$. The proof of part (b) is similar to that of Proposition 3.2.

Just as in the previous commitment case, states of demand can be ordered in a simple way: if $P_{i}^{O}=P_{i}^{*}$, then $P_{i+1}^{O}=P_{i+1}^{*}, \ldots, P_{n}^{O}=P_{n}^{*}$. Conversely, if $P_{i}^{O}>P_{i}^{*}$, then $P_{i-1}^{O}>P_{i-1}^{*}, \ldots, P_{1}^{O}>P_{1}^{*}$. Contrary to the case of commitment, however, the optimal no-commitment contract always gives full insurance to the franchise holder. Consequently, when $\mathrm{PVR}_{i}^{*} \geq I$ in all states, the solution to problem (12) is identical to the commitment contract: in all states the franchise ends when $\mathrm{PVR}_{i}=I$. But when $\mathrm{PVR}_{i}^{*}<I$ in at least one state of demand, the optimal contract is inferior to the commitment contract. First, the participation constraint must not only hold on average, but in every state of demand. Thus, insurance and distorted tolls cannot be traded off and this contract gives too much insurance and distorts tolls too much. Second, roads for which $\mathrm{PVR}^{M}<I$ in at least one state of demand will never be built, independently of their profitability in other states, whereas they might have been built under the optimal commitment contract.

\footnotetext{
${ }^{28}$ See footnote 9 for evidence.
} 
Note that the optimal no-commitment contract is analogous in spirit to traditional rate of return regulation, which seeks to set the price of the service so that the public utility earns a normal rate of return contingent on the particular realization of demand and cost parameters. ${ }^{29}$ The main difference is that the franchise period is limited, a consequence of the assumption that all investments are sunk and need to be made only once.

\subsection{Additional results}

It is interesting to relate the optimal contracts with Ramsey pricing. We first note that the commitment case corresponds to the Ramsey assumption of a single budget constraint, while the no commitment case considers a "per service" budget constraint.

Next we describe how, in the case with commitment, ${ }^{30}$ optimal tolls and franchise lengths vary as the construction cost $I$ increases. We start with a sufficiently low value of $I$, so that in all states of demand the road can be financed with congestion tolls in finite time. ${ }^{31}$ As $I$ increases in this range, the optimal franchise length increases, with no change in tolls, since additional revenue can be collected in all states of demand without distorting tolls. In contrast to standard Ramsey problems, the additional instrument available in our case, namely the franchise length, makes it possible to collect more revenue without creating distortions.

Once $I$ exceeds $\mathrm{PVR}_{1}^{*}$, the optimal toll in state 1 will be above the corresponding congestion toll, $P_{1}^{*}$. When trading off toll distortions and the risk premium, the planner always chooses a positive level of toll distortion, since the associated welfare cost is second order while that associated with increasing the risk premium is first order. As $I$ continues increasing, the franchise lengths in states 2 through $n$ continue increasing. By contrast, in state 1 it is the toll that increases, aiming at keeping a balance between the toll distortion this creates and the risk premium associated with the lower present value of revenue that the franchise holder receives in this state. Eventually $I$ reaches a threshold where the franchise length in state 2 is infinite. Values of $I$ above this threshold lead to distortionary tolls in states 1 and 2.

As $I$ continues increasing, distortionary tolls (and indefinite franchise lengths) set in, consecutively, in states 3, 4, and so on. By the time $I>\mathrm{PVR}_{n}^{*}$, distortionary tolls (and indefinite franchise lengths) are required in all states of demand.

It follows from our discussion above that for a particular state $k$ the present value of revenue collected during the franchise increases monotonically with $I$. For small values of $I$ it is an increasing franchise length that accounts for this increase; for larger values the franchise length is indefinite and additional revenue is collected by increasing the toll.

The results described above can be summarized in the following proposition:

\footnotetext{
${ }^{29}$ Since demand is exogenous in the present model, there is no tradeoff between rent extraction and incentives. Moreover, in this section the regulator acts with full information about the relevant parameters. Thus, rent extraction is the sole aim of the regulator and rate of return regulation is appropriate.

${ }^{30}$ All of what follows has an obvious counterpart in the case without commitment.

${ }^{31}$ Since we adopted the convention that $\mathrm{PVR}_{i}^{*} \leq \mathrm{PVR}_{j}^{*}$ if $i<j$ this is equivalent to $\mathrm{PVR}_{1}^{*}>I$.
} 
Proposition 3.7 (Increasing revenue as a function of $I$ ) The present value of revenue collected in a given state of demand by the optimal contract is a strictly increasing function of the construction cost I, both in the case with and without commitment.

Proof See EFG (1998).

The above digression motivates a classification of roads according to whether the optimal contract requires toll distortions:

1. High-demand road: In all states of demand the optimal toll is equal to the congestion toll, i.e., there are no distorted states. ${ }^{32}$

2. Intermediate demand road: There exists an index $k$ between 2 and $n$, such that the optimal contract's toll in state $i$ is above the corresponding congestion toll for all $i<k$ and equal to the congestion toll all $i \geq k$. that is, there are some states with distortionary tolls.

3. Low-demand road: In all states the optimal toll is higher than the congestion toll.

\section{Least-Present-Value-of-Revenue auctions}

In this section we show how the optimal contract derived in the preceding section can be implemented with a competitive auction. Auctioning a highway franchise requires designing the franchise contract and choosing a bidding variable. Since the auction takes place before demand is realized, the bidding variable cannot be state-contingent. Implementing the optimal contract via a competitive auction therefore requires finding a bidding variable that does not vary across states of demand and that can replicate the optimal franchise lengths and tolls, both of which vary with demand.

If the regulator sets the franchise term and firms compete on the lowest toll, the resulting contract has a toll that is equal to the winning bid, and therefore constant across states of demand. It follows that the optimal contract cannot be replicated in this way. This holds even if the length of the franchise is demandcontingent. Similarly, if the regulator sets state-contingent tolls and firms compete on the shortest franchise term, the resulting contract cannot be optimal since its length does not vary with demand realizations.

In this section we show that the bidding variable that solves the problem described above is the present value of toll revenue. The corresponding auction proceeds as follows: First, the regulator announces the discount rate and the toll that the franchise holder will be allowed to charge in each state of demand. This toll is the optimal contract toll in each state of demand. Second, firms bid on the present value of toll revenue and the lowest bid wins the franchise contract. The road is built, the planner observes the state of demand and sets the corresponding optimal toll. The franchise holder collects tolls until the present value of tolls equals the winning bid, then the road is transferred to the state. If the sum is never collected, the

\footnotetext{
${ }^{32}$ It is interesting to note that urban highways are likely to be high-demand roads.
} 
franchise lasts forever. In the next section we show that this Least-present-value-of-revenue (LPVR) auction implements the optimal contract. We consider separately the cases of high-, intermediate- and low-demand roads.

\subsection{High-demand road}

It follows from Section 3 that in this case the optimal contract involves the same present value of revenue, $I$, in all states of demand. ${ }^{33}$ It is also easy to see that the winner's expected utility is an increasing function of her (winning) bid. Also, a bid equal to $I$ achieves the break-even point. Thus, Nash competition between identical firms implies that the winner will bid $I$. If state $k$ occurs, the franchise term, $T_{k}$, is such that present value of toll revenue during the franchise is equal to $I$. Thus $T_{k}$ is determined from:

$$
\int_{0}^{T_{k}} P_{k}^{O} Q_{k}\left(P_{k}^{O}\right) e^{-r t} d t=I,
$$

which is precisely the condition for the optimal contract's franchise length, $T_{i}^{O}$. It follows that the LPVR auction implements the optimal contract.

It is interesting to note that in the case of a high demand road the regulator does not need to know the probability distribution of states of demand or firms' utility functions in order to implement the optimal contract. The only information she needs are the optimal congestion tolls.

In the case of intermediate and low-demand roads, an analogous argument shows that an LPVR auction implements the optimal contract in the cas of no commitment. The case with commitment is more difficult and we turn to it next.

\subsection{Intermediate- and low-demand roads}

We begin with an intermediate demand road. For $i \geq k$ the optimal contract sets congestion tolls, while in the remaining states $(i<k)$ it sets distortionary tolls and the franchise lasts forever.

It is obvious that in an LPVR auction the franchise holder's expected utility is an increasing function of her (winning) bid. Next we show that her participation constraint holds with equality when she bids the present value of revenue common to all states where the optimal contract sets congestion tolls (that such a value exists follows from Proposition 3.3). This, combined with the fact that the winning bid leads to the same franchise length as the optimal contract in all states of demand, implies that Nash competition between identical firms replicates the optimal contract.

Since the present value of revenue is higher in states with congestion tolls than in states with distortionary tolls (Proposition 3.4), we have that the franchise lasts indefinitely when one of the lower demand states occurs, as is the case under the optimal contract. In high-demand states, the argument of the previous section shows that the LPVR and the optimal contract coincide.

\footnotetext{
${ }^{33}$ This holds both for the case with and without commitment.
} 
Denote by $\operatorname{PVR}_{i}^{O}$ the present value of revenue collected by the franchise holder with the optimal contract in state $i$. An LPVR auction implements the optimum because a firm bidding $\max _{i} \mathrm{PVR}_{i}^{O}$ will collect $\mathrm{PVR}_{i}^{O}$ in state $i$, as long as the regulator sets the optimal toll corresponding to state $i$. In the case of a high-demand road, all the $\mathrm{PVR}_{i}^{O}$ 's are equal to $I$. By contrast, in the case of an intermediate demand road, $\max _{k} \mathrm{PVR}_{k}$ is equal to the common revenue obtained in all those states where the optimal toll equals the corresponding congestion toll. Noting that the winning bid will also be $\max _{i} \mathrm{PVR}_{i}$, an argument similar to the one given for an intermediate demand road can be used to show that an LPVR auction is optimal for a low-demand road.

\subsection{Informational requirements}

The informational requirements needed to implement the optimum are quite formidable in the case of an intermediate or low-demand road with commitment. The regulator needs to know construction costs $I$, the probability distribution of demand states, $\pi_{i}$, and the demand schedules, $Q_{i}, i=1, \ldots, n$. By contrast, we showed that in the case of a high-demand road the regulator does not need to know neither $I$ nor the $\pi_{i}$ 's, since knowing the congestion tolls suffices in this case.

Since the winning bid, $\max _{i} \mathrm{PVR}_{i}^{O}$, is (strictly) increasing in $I$ (see Proposition 3.7), the regulator can use this relation to infer $I$ from the winning bid. Thus, knowledge of $I$ is not necessary to implement the optimal contract not only in the case of high-demand roads, but also in the case of intermediate and low-demand roads. This holds both in the case with and without commitment.

The results derived in this section are summarized in the following proposition:

Proposition 4.1 Denote by $\max _{i} P V R_{i}^{O}(I)$ the maximum, over all states of demand, of the present value of revenue collected under the optimal contract when construction costs equal I. ${ }^{34}$

Then an LPVR auction implements the social optimum if the regulator announces that for a winning bid of $\beta$ the toll schedule will be the optimal state-contingent tolls associated with the value of I that satisfies $\max _{i} P V R_{i}^{O}(I)=\beta .^{35}$ This holds both for the cases with and without commitment.

Proof The main elements of the proof we discussed in this section. A more formal approach is in EFG (1998).

Having established the optimality of LPVR auctions, we note that fixed-term auctions, which are the standard highway auction mechanisms throughout the world, are optimal only if $\mathrm{PVR}_{i}^{*}$ is the same across all states of demand and the common value is larger than $I$. Thus generically fixed-term auctions are suboptimal. ${ }^{36}$ Furthermore, as we show in the next section, not only are LPVR auctions better than their fixed-term counterpart, but welfare differences are important.

\footnotetext{
${ }^{34}$ Regarding possible values of $I$, see EFG (1998).

${ }^{35}$ That such a value of $I$ exists and is unique follows from Proposition 3.7.

${ }^{36}$ For a formal proof see Appendix C in EFG (1998).
} 


\section{$5 \quad$ LPVR and fixed-term franchises compared}

As we mentioned before, most highways that have been franchised around the world have been awarded under a fixed-term contract. In this section we develop a procedure to quantitatively compare LPVR auctions with fixed-term auctions and apply it to data from Chilean highways to obtain estimates of the savings involved in using an LPVR auction (a massive highway franchising program is currently underway in Chile, see EFG [1996]). Since we do not have data to estimate demand elasticities we work with a simplified version of the model where demand in each state is perfectly inelastic. Uncertainty comes from the fact that demand depends on user income, whose growth is stochastic. Given that tolls play no allocational role in this setting, we also assume that in all states of demand the toll is the same and high enough to finance the road.

\subsection{Model}

In a fixed term auction the planner can either set the franchise term $T$ and the auction is won by the firm who bids the lowest toll; or it can fix a toll $P$ and the auction is won by the firm who bids the shortest franchise term. In both cases Nash competition implies that the following identity must hold in equilibrium:

$$
\sum_{i} \pi_{i} u\left(P \cdot \mathrm{PVQ}_{i}(T)-I\right)=u(0)
$$

Where $\mathrm{PVQ}_{i}(T)$ denotes the present value of traffic flow in state of demand $i,{ }^{37}$ and $\mathrm{PVR}_{i}=P \cdot \mathrm{PVQ}_{i}$. Note that if the term of the franchise is fixed, $\mathrm{PVQ}_{i}$ varies with the state of demand. Thus with a fixed-term franchise the franchise holder cannot be offered full insurance. By contrast, an LPVR auction gives full insurance to the franchise holder.

Let $\zeta(T) \equiv E\left[\mathrm{PVQ}_{i}(T)\right]$ be the expected present value of traffic flows if the term of the franchise is $T$, and let $\sigma^{2}(T) \equiv E\left[\left[\mathrm{PVQ}_{i}(T)-\zeta(T)\right]^{2}\right]$ denote the corresponding variance. Proposition 5.1 calculates the risk premium charged by the franchise holder in a fixed-term auction.

Proposition 5.1 To a first order approximation, the risk premium charged by the franchise holder in a fixed-term franchise is

$$
\left(\frac{C V \sqrt{A / 2}}{1-C V \sqrt{A / 2}}\right) I .
$$

Where Adenotes the coefficient of relative risk aversion (evaluated at $P \zeta-I$ ) and $C V \equiv \sigma / \zeta$ denotes the coefficient of variation of the present value of traffic flows.

Proof Given $T$ or $P$, equilibrium tolls or franchise terms are determined by condition (13). A first-order Taylor expansion of the RHS of (13) and a second-order Taylor expansion of the LHS, both around the risk

\footnotetext{
${ }^{37}$ Note that $Q_{i}$ is no longer a function of $P_{i}$. Also note that, in contrast with the preceding sections, we do not assume that uncertainty is resolved in the first period.
} 
premium $P \zeta(T)-I$, lead to:

$$
\sum_{i} \pi_{i}\left[\bar{u}+P\left(\mathrm{PVQ}_{i}-\zeta\right) \bar{u}^{\prime}+\frac{1}{2} P^{2}\left(\mathrm{PVQ}_{i}-\zeta\right)^{2} \bar{u}^{\prime \prime}\right] \cong \bar{u}-(P \zeta-I) u^{\prime}
$$

Where $\bar{u} \equiv u(P \zeta(T)-I), \bar{u}^{\prime} \equiv u^{\prime}(P \zeta(T)-I)$ and $\bar{u}^{\prime \prime} \equiv u^{\prime \prime}(P \zeta(T)-I)$. It follows that $-\frac{1}{2} P^{2} \sigma^{2} \frac{\bar{u}^{\prime \prime}}{\bar{u}^{\prime}} \cong P \zeta-I$, and hence, multiplying both sided by $P \zeta-I$

$$
\frac{1}{2} P^{2} \sigma^{2} A \cong(P \zeta-I)^{2}
$$

which leads to

$$
P \cong \frac{I}{\zeta[1-C V \sqrt{A / 2}]}
$$

Substituting $P$ back into (15) and taking the square root yields (14) which completes the proof.

Now consider an LPVR auction. If tolls are set high enough to make the road self-financing in all states, ${ }^{38}$ then the following corollary follows trivially:

Corollary 5.1 If the toll $P$ is fixed so that the road is self-financing in all states, then expression (14) is also the expected value of the reduction in toll income in a competitive auction.

\subsection{Empirical implementation}

We calculate risk premia for values of $A$ between 1.0 and 3.0 (see Table 1). ${ }^{39}$ We obtain $C V$ as follows. We assume that traffic flows increase according to

$$
Q_{t+1}=e^{g_{t}} Q_{t}
$$

and define

$$
\mathrm{PVQ} \equiv \sum_{t=0}^{T-1} e^{-r t} Q_{t}
$$

There are two sources of uncertainty: the annual growth rates of the traffic flow, $g_{t}$, and the initial traffic flow, $Q_{0}$. We assume that annual growth rates are independently distributed and satisfy

$$
g_{t} \equiv\left(\eta_{y}+\varepsilon_{t}^{\eta}\right)\left(g_{y}+\varepsilon_{t}^{M}+\varepsilon_{t}^{m}\right)
$$

Where $\eta_{y}$ denotes the average income elasticity of traffic flows, $\varepsilon_{t}^{\eta}$ are random shocks that affect this elasticity, $g_{y}$ is the average growth rate of GDP, and $\varepsilon_{t}^{M}$ and $\varepsilon_{t}^{m}$ are, respectively, the variations in this rate due

\footnotetext{
${ }^{38}$ Since demand is inelastic, general equilibrium considerations ignored throughout this paper suggest that the toll should be set equal to road users' reservation toll.

${ }^{39}$ These values are representative of those estimated in the literature.
} 
Table 1: SAVINGS AS A PERCENTAGE OF ORIGINAL INVESTMENT

\begin{tabular}{ccccccc}
\hline \hline & & \multicolumn{5}{c}{ Coef. Rel. Risk Aversion } \\
& & 1.0 & 1.5 & 2.0 & 2.5 & 3.0 \\
\hline \multirow{4}{*}{ CV } & $0.05:$ & 16.6 & 21.1 & 25.2 & 29.0 & 32.7 \\
of & $0.10:$ & 18.4 & 23.5 & 28.2 & 32.6 & 36.8 \\
$Q_{0}$ & $0.15:$ & 21.2 & 27.3 & 32.9 & 38.3 & 43.5 \\
& $0.20:$ & 24.8 & 32.2 & 39.1 & 45.8 & 52.5 \\
& $0.25:$ & 29.3 & 38.4 & 47.2 & 55.9 & 64.6 \\
\hline
\end{tabular}

to macro- and micro-economic factors. The parameter $\eta_{y}$ is taken as 1.6 , the estimated income elasticity of traffic flows in Chile in the period 1985-1995; $g_{y}$ is set equal to 0.06, the average rate of growth of Chile's GDP over the same period; $\varepsilon_{t}^{\eta}, \varepsilon_{t}^{M}$ and $\varepsilon_{t}^{m}$ are assumed to be mutually independent and uncorrelated over time, following a normal distribution with zero mean and standard deviations of, respectively, 0.2, 0.02 and 0.04. The standard deviations assumed for macro- and micro-economic risk are consistent with the growth rates of national and regional GDP in Chile over the 1985-1995 period. ${ }^{40}$ The variation of $Q_{0}$ cannot be estimated from actual data. Thus, as in the case of the coefficient of relative risk aversion, we calculate risk-premia for values of the coefficient of variation of initial traffic between 0.05 and 0.25 .

If the length of the franchise $(T)$, the discount rate $(r)$, the relative risk aversion coefficient $(A)$ and the coefficient of variation of $Q_{0}$ are all given, the coefficient of variation of the sum (16) can be estimated by simulating paths for $g_{t}$. We assume that $T=20$ years (several highways in Chile were franchised with that term) and $r=0.06$ (this has been close to the average real rate paid by a 20-year bond issued by the Central Bank during the nineties). $C V$ can be calculated assuming that traffic growth rates are independent from the initial level and holding constant the coefficient of variation of $Q_{0}{ }^{41}$

Table 1 shows the savings to users as a percentage of the initial investment, for alternative combinations of the coefficient of variation of $Q_{0}$ and the relative risk aversion coefficient, $A{ }^{42}$

It can be read from Table 1 that if the coefficient of risk aversion of firms is 2 and the coefficient of variation of $Q_{0}$ is 0.15 , then the risk premium charged by the franchise holder if the term is fixed is approximately one-third (32.9\%) of the initial investment. The median of the values in the table is $32.6 \%-$ the mean is even higher. With a discount rate of $8 \%$ instead of $6 \%$, the median is $31.1 \%$.

\footnotetext{
${ }^{40}$ The standard deviations for $\varepsilon_{t}^{M}$ and $\varepsilon_{t}^{m}$ are obtained decomposing yearly regional GDP growth rates into the sum of a common component (equal to the average growth rate across regions) and an idiosyncratic component (the residual). The standard deviation of the common component is $1.82 \%$, the standard deviation of idiosyncratic shocks varies between $2.79 \%(1989-1990)$ and $5.75 \%$ (1993-1994) with an average of $4.21 \%$ over the period considered. We thank Raimundo Soto for providing the regional GDP data.

${ }^{41}$ Here we use the result that relates the coefficient of variation of the product of two independent variables, $X$ and $Y$, to the coefficient of variation of the individual variables: $C V_{X \cdot Y}^{2}=C V_{X}^{2}+C V_{Y}^{2}+C V_{X}^{2} \cdot C V_{Y}^{2}$.

${ }^{42}$ Each value in this table is based upon a coefficient of variation of the sum (16) obtained from 25,000 simulations. This leads to a relative approximation error smaller than $0.4 \%$.
} 


\section{Conclusion}

In this paper we have shown that fixed-term contracts, which are commonly used to franchise highways, do not allocate demand risk optimally. We characterized the optimal risk sharing contract and showed that it can be implemented with a fairly straightforward mechanism — an LPVR auction. Instead of bidding on a toll (or a franchise length), as in the case of fixed term franchises, in an LPVR auction the regulator sets a toll schedule and bidders announce present values of toll revenues. The lowest bid wins and the franchise ends when that amount has been collected. Finally, we showed that the welfare gains that can be attained by replacing fixed-term auctions with LVPR auctions are substantial.

Throughout the paper we focused on the risk sharing properties of alternative highway franchising contracts. Worldwide evidence with highway franchising suggests that there are additional characteristics of these contracts that should be considered. We comment on them briefly. ${ }^{43}$

Since the franchise term adjusts to demand realizations, LPVR auctions are much less sensitive to demand information and thus more cost oriented than fixed term franchises. For example, if we allow for heterogeneity in construction costs and assume that all bidders can recuperate their building costs with congestion tolls, then in a second-price LPVR auction all firms will bid their construction cost, no resources will be spent on estimating demand, and the winner will be the most efficient firm. By contrast, in the case of a fixed term franchise, demand realizations affect bidders' profits, so that bidders have incentives to spend resources on estimating demand. Furthermore, in this case it is likely that the winner will not be the firm with lowest construction costs, since bids will also reflect differences in demand forecasts.

The actual experience of countries that have franchised highways to the private sector has often been unhappy. Two problems have been prominent: private firms and financiers usually refuse to participate unless governments pledge guarantees against commercial risks; ${ }^{44}$ and franchise holders are generally able to renegotiate and shift losses to taxpayers and users whenever they get into financial trouble. ${ }^{45}$ As we have argued elsewhere (see EFG [1997b]), government guarantees and renegotiations are undesirable, because they are not accounted for in the budget, blunt the incentives to be efficient, encourage firms with experience in lobbying to lowball in the expectation of a future renegotiation, and make white elephants more likely. ${ }^{46}$ We believe LPVR franchises moderate these pitfalls. ${ }^{47}$ By reducing demand risks, they reduce the demand for guarantees. Moreover, the fact that each firm's bid reveals the income required to earn a normal profit reduces the scope for post-contract opportunistic renegotiations, since any wealth transfer by the government must take the form of a cash transfer whose amount can be readily understood by the public and compared with the initial winning bid. For the same reason, it should be politically more difficult for the government to exploit the franchise holder by changing the original contract, since the winning bid is a clear and observable

\footnotetext{
${ }^{43}$ The presentation is at an intuitive level since we are currently working on formalizing these insights.

${ }^{44}$ For example, for nine out of ten highways franchised in recent years in Chile, the government provided a guarantee that the revenue would equal $70 \%$ of construction and maintenance costs. See Irwin et et al. (1997) for more examples.

${ }^{45}$ See footnote 9.

${ }^{46}$ Where by white elephant we mean a road with negative net present social value.

${ }^{47}$ And are therefore more robust to Williamson's $(1976,1985)$ critique of franchise bidding.
} 
benchmark that makes it easy to value any wealth expropriation.

LPVR auctions also are more flexible than their fixed term counterparts. For example, if for some reason, the franchise needs to be terminated ahead of time, a fair compensation for the franchise owner is the difference between the winning bid and revenue collected thus far. ${ }^{48}$ This should be contrasted with fixed term franchises, where compensations based on estimates of expected profits during the remainder of the franchise are subject to dispute. ${ }^{49}$ Underlying this intuition is the fact that an LPVR franchise is an incomplete contract where one of the parties (the franchise holder) has little to fear if the other party (the regulator) is given full ex post control (in the Grossman-Hart-Moore sense). The government can react to unforeseen circumstances in a variety of ways without affecting the franchise holder's profits, since the franchise holder only cares about eventually recovering the up front investment. This implies that under LPVR, the government has more flexibility to react to demand realizations, than under a fixed term scheme.

The main caveat regarding LPVR auctions is that they provide insufficient incentives to exert effort in demand- and quality-enhancing activities (e.g. building a road of the right standard, providing adequate maintenance without supervision, or providing expeditious service at toll booths). For example, potholes reduce demand for the road, yet the franchise owner has few incentives to maintain the road adequately, since the associated revenue shortfall will be made up through a longer franchise length. Throughout the paper we assumed that demand was exogenous, thereby ignoring the insurance-quality tradeoff. In the case of monopoly highways, there appear to be few demand enhancing activities, so omitting the effects of incentives appears reasonable. Nevertheless, as Tirole (1997) has stressed, this suggests that LPVR contracts should be complemented with other regulatory innovations, such as third parties who verify minimum quality standards, and appropriate fines for non-compliance. In the case of highway franchises this should not be a major problem since objective measures for road and service quality can be defined and verified at a low cost, yet this sets limits to the application of LPVR auctions to other types of infrastructure projects. ${ }^{50}$

Finally it is interesting to mention that LPVR auctions are not only a theoretical construct. An LPVR auction was used in February of 1998 in Chile to franchise the Santiago-Valparaíso-Viña del Mar concession. The project contemplates major improvements and extensions of the 100 mile highway and the construction of three tunnels, with estimated costs of almost US\$400 million. The toll schedule was fixed in advance (in real terms) as was the discount rate. Five firms participated in the auction and the present value of toll revenue demanded by the winner turned out to be below estimated construction and maintenance costs. One possible explanation for this outcome is that, given the relatively low risk associated with LPVR auctions, the discount rate set by the regulator-equal to the risk free rate plus 4\%—was higher than the discount rate used by firms. Also, firms were given the option to buy government insurance against demand risks, but the

\footnotetext{
${ }^{48}$ We have ignored maintenance costs throughout this paper. If they are added, an estimate for savings associated with these cost should be subtracted.

${ }^{49}$ In early 1997 the government of Argentina announced it wanted to end airport franchises in order to reauction them under new terms. These were fixed-term franchises. Estimates of adequate compensation for franchise holders varied between US $\$ 400$ million (government estimates) and US\$40 million (former Economics Minister Domingo Cavallo's estimates). See El Mercurio, February 6, 1997.

${ }^{50}$ Another case where LPVR auctions are appropriate is water reservoirs.
} 
winner declined the offer.

\section{References}

[1] Arrow, K., and R. Lind, "Uncertainty and Public Investment Decisions", American Economic Review, 60, 364-78, 1970.

[2] Chadwick, E., "Results of Different Principles of Legislation in Europe," Journal of the Royal Statistical Society, Series A22, 381-420, 1859.

[3] Demsetz, H., "Why Regulate Utilities”, Journal of Law and Economics, 11, 55-66, 1968.

[4] Engel, E. M. R. A., R. D. Fischer and A. Galetovic, "Highway Franchising in Chile", Estudios Públicos, 60, 5-37, 1996, in Spanish.

[5] - "Highway Franchising: Pitfalls and Opportunities", American Economic Review Papers and Proceedings, 87:2, 68-72, 1997a.

[6] - "Infrastructure Franchising and Government Guarantees," Chapter 4 in T.Irwin, M.Klein, G.Perry and M.Thobani (eds), Dealing with Public Risk in Private Infrastructure, Washington, D.C.: The World Bank, 1997b.

[7] —, "Least-Present-Value-of-Revenue Auctions and Highway Franchising," Working Paper No. 37, Center for Applied Economics (CEA), University of Chile. 1998. http://www.dii.uchile.cl/ cea/index.html

[8] Gómez-Ibáñez, J.A., and J. Meyer, Going Private: The International Experience with Transport Privatization, Washington, D.C.: The Brookings Institution, 1993.

[9] Irwin, T., M. Klein, G. Perry and M. Thobani (eds), Dealing with Public Risk in Private Infrastructure, Washington, D.C.: The World Bank, 1997.

[10] Laffont, J., and J. Tirole, A Theory of Incentives in Procurment and Regulation, Cambridge, Mass.: MIT Press, 1993.

[11] Posner, R., "The Appropriate Scope of Regulation in Cable Television," The Bell Journal of Economics 3, 335-358, 1972.

[12] Riordan, M. and Sappington, D. "Awarding Monopoly Franchises", American Economic Review 77, 375-387, 1987 
[13] Small, K., Winston, C. and Evans, C. Road Work: A New Highway Pricing and Investment Policy, Washington D.C.: Brookings Press, 1989.

[14] Stigler, G. J., The Organization of Industry, Homewood, Ill.: Richard D. Irwin, 1968.

[15] Tirole, J., "Comment on a Proposal of Engel, Fischer y Galetovic on Highway Auctions," Estudios Públicos, 65, 201-214, 1997, in Spanish.

[16] Williamson, O. E., "Franchise bidding for natural monopolies-in general and with respect to CATV," Bell Journal of Economics, 7 (Spring), 73-104, 1976.

[17] Williamson, O. E., The Economic Institutions of Capitalism, New York: Free Press, 1985. 


\section{Appendix}

Proposition 7.1 There exists a solution for the social planner's problem with commitment.

Proof The implicit function theorem and (6) can be used to express $P_{1}^{F}$ as a function of the remaining $P_{i}^{F}$ 's and of the $L_{i}$ 's. This expression can be used to rewrite the planner's problem as an unconstrained maximization problem over all $L_{i}$ 's and $P_{2}^{F}, P_{3}^{F}, \ldots, P_{n}^{F}$. From (8) we then have that the planner is maximizing a continuous function over a compact set. Existence of a solution now follows.

As will become clear shortly, the following functions are closely related to the degree to which the self-financing constraint leads to distortions in a particular state of demand.

Definition 7.1 (Distortion functions) We define:

$$
\begin{aligned}
H_{i}(P) & \equiv \frac{Q_{i}(P)\left(1+\eta_{i}(P)\right)}{Q_{i}(P)\left(1+\eta_{i}(P)\right)-G_{i}^{\prime}(P)}, \\
v_{i}(P, L) & \equiv H_{i}(P) u^{\prime}\left(P V R_{i}(P, L)-I\right),
\end{aligned}
$$

where:

$$
P V R_{i}(P, L) \equiv \frac{P Q_{i}(P)}{r}(1-L)
$$

Lemma 7.1 The functions $H_{i}(P)$ satisfies $H_{i}(P)<1$, for all $P>P_{i}^{*}$.

Proof The result follows from the fact that $G_{i}$ is concave and attains its maximum at $P_{i}^{*}$.

Theorem 7.1 (Optimality conditions) The planner's solution to the problem with commitment satisfies $P_{i}^{O}>0$ and $T_{i}^{O}>0$ for all states $i$. Also, for any pair of states $k$ and $l$ we have:

$$
v_{k}\left(P_{k}^{O}, L_{k}^{O}\right)=v_{l}\left(P_{l}^{O}, L_{l}^{O}\right)
$$

or equivalently:

$$
H_{k}\left(P_{k}^{O}\right) u_{k}^{\prime}=H_{l}\left(P_{l}^{O}\right) u_{l}^{\prime}
$$

Where $v_{i}(P, L)$ is defined in (17) and $u_{i}^{\prime}=u^{\prime}\left(\mathrm{PVR}_{i}^{O}-I\right)$.

Proof We divide the states of demand in two groups. The first group includes those states where $L_{k}^{O}<1$ (or equivalently $T_{k}^{O}>0$ ) and $P_{k}^{O}>0$. The second group includes all the remaining states, that is those where either $L_{k}^{O}=1$ or $P_{k}^{O}=0$. Note that $P_{k}^{O}$ can take any value when $L_{k}^{O}=1$, since $T_{k}^{O}=0$ in this case. Thus we may assume, without loss of generality, that $P_{k}^{O}=0$ and $L_{k}^{O}<1$ for all states in the second category. 
The first group of states has to be non-empty, since otherwise the firm's participation constraint cannot be satisfied (all states in the second group provide no revenue for the firm). The initial statement of the proposition is that all states belong to the first group.

The remainder of the proof proceeds as follows. We first prove (18) for any pair of states in the first category. Next we show that no state can belong to the second group.

The Lagrangian corresponding to the social planner's problem is:

$$
\mathcal{L}=\frac{1}{r} \sum_{i=1}^{n} \pi_{i}\left\{\left[G_{i}\left(P_{i}^{F}\right)-P_{i}^{F} Q_{i}\left(P_{i}^{F}\right)\right]\left(1-L_{i}\right)+G_{i}\left(P_{i}^{A}\right) L_{i}\right\}+\lambda \sum_{i=1}^{n} \pi_{i} u\left(\mathrm{PVR}_{i}-I\right)
$$

The first order condition in $P_{k}^{F}$ for a state in the first category implies:

$$
v_{k}\left(P_{k}^{O}, L_{k}^{O}\right)=\frac{1}{\lambda}
$$

so that (18) holds for any pair of states $i$ and $k$ in this category.

If state $k$ belonged to the second category, we would have:

$$
v_{k}\left(P_{k}^{O}, L_{k}^{O}\right) \leq \frac{1}{\lambda}
$$

From Corollary A.1 in EFG (1998) and (8) we have that $P_{k}^{*}=0$ and $c(Q)$ is constant. Thus (26) implies that $G^{\prime}\left(P_{k}^{O}\right)=0$, and hence $H_{k}\left(P_{k}^{O}\right)=1$. It follows from (19), (20) and (48) in EFG (1998) that:

$$
\begin{aligned}
& u_{k}^{\prime} \leq \frac{1}{\lambda} \\
& u_{l}^{\prime} \geq \frac{1}{\lambda}
\end{aligned}
$$

Where $l$ is a state in the first category. Concavity of $u$ and the two preceding inequalities imply that the revenue obtained by the firm in state $k$ is larger or equal than that obtained in state $l$. Since the former is zero, the latter is also zero. This contradicts the firms' participation constraint, thus showing that there exist no states in the second category.

Corollary 7.1 If $P V R_{i}^{*} \leq P V R_{j}^{*}$ and $P_{i}^{O}=P_{i}^{*}$ then $P_{j}^{O}=P_{j}^{*}$.

Proof We assume $P_{j}^{O}>P_{j}^{*}$ and arrive at a contradiction.

If $P_{j}^{O}>P_{j}^{*}$, then $T_{j}^{O}=\infty$ (Proposition 3.2). Since $H_{j}\left(P_{j}^{O}\right)<1$ and $H_{i}\left(P_{i}^{O}\right)=1$ (Lemma B.1 in EFG 
[1998]), from Theorem 7.1 it follows that $u_{i}^{\prime}<u_{j}^{\prime}$ and therefore

$$
\operatorname{PVR}_{i}^{O}>\operatorname{PVR}_{j}^{O}
$$

On the other hand, since demand is relatively inelastic (see Proposition A.2 in EFG [1998] for a formal proof) and in view of condition (8) it follows that:

$$
\mathrm{PVR}_{j}^{O}>\mathrm{PVR}_{j}^{*}
$$

Also, trivially (since the optimal toll is $P_{i}^{*}$ ) we have:

$$
\mathrm{PVR}_{i}^{O} \leq \mathrm{PVR}_{i}^{*}
$$

From (23), (21) and (22):

$$
\mathrm{PVR}_{i}^{*} \geq \mathrm{PVR}_{i}^{O}>\mathrm{PVR}_{j}^{O}>\mathrm{PVR}_{j}^{*}
$$

and therefore $\mathrm{PVR}_{i}^{*}>\mathrm{PVR}_{j}^{*}$, contradicting one of our assumptions. 


\section{Less Important Appendices}

\section{A Concavity of $G_{i}$}

In this appendix we prove concavity of the net instantaneous social welfare function, $G_{i}$. The notation and definitions are those given in the main text.

Proposition A.1 (Existence of a demand function) Given a price $P$ the demand schedule in state $i, Q_{i}(P)$, is determined implicitly by

$$
B_{i}\left(Q_{i}(P)\right)-c\left(Q_{i}(P)\right)=P .
$$

We also have:

$$
\begin{aligned}
Q^{\prime}(P) & =\left[B^{\prime}(Q(P))-c^{\prime}(Q(P))\right]^{-1}<0, \\
Q^{\prime \prime}(P) & =-\frac{\left[B^{\prime \prime}(Q(P))-c^{\prime \prime}(Q(P))\right]}{\left[B^{\prime}(Q(P))-c^{\prime}(Q(P))\right]^{3}} \leq 0 .
\end{aligned}
$$

Where in the last two expressions we dropped the subscript i for ease of presentation. ${ }^{51}$

Proof Since the generalized travel cost is $P+c(Q)$, in equilibrium the number of cars on the road is determined by (24), as long as there exists a $Q \geq 0$ satisfying this condition. From assumptions (2) and (3) it follows that such a $Q$ exists (and is unique) as long as $P$ is below some state-specific maximum toll $\hat{P}_{i}$.

The expressions for $Q^{\prime}(P)$ and $Q^{\prime \prime}(P)$ follow from implicitly differentiating (24) with respect to $P$.

From the above proof it is evident that $\hat{P}_{i}$ defines the threshold toll beyond which demand is zero and $Q_{i}(0)$ defines the maximum demand that can attain, both in state $i$. In the statements we make in the remainder of this appendix, unless otherwise stated $P$ and $Q$ will take values in $\left[0, \hat{P}_{i}\right]$ and $\left[0, Q_{i}(0)\right]$, respectively.

Definition A.1 (Net Social Surplus, Elasticity) It will be helpful to define net social surplus as a function of $Q$ :

$$
\tilde{G}_{i}(Q) \equiv \int_{0}^{Q} B_{i}(q) d q-Q c(Q) .
$$

We define the price-elasticity of demand and (instantaneous) revenue in state $i$ at price $P$ as

$$
\eta_{i}(P) \equiv \frac{P Q_{i}^{\prime}(P)}{Q_{i}(P)}
$$

\footnotetext{
${ }^{51}$ We will do this often throughout this appendix.
} 
and

$$
\mathcal{R}_{i}(P)=P Q_{i}(P)
$$

Lemma A.1 The net social surplus, as a function of $P$, satisfies:

$$
\begin{aligned}
G^{\prime}(P) & =Q(P)\left[\eta(P)-c^{\prime}(Q(P)) Q^{\prime}(P)\right] \\
G^{\prime \prime}(P) & =\frac{-\left(B^{\prime \prime}-c^{\prime \prime}\right)\left(B-c-Q c^{\prime}\right)+\left(B^{\prime}-c^{\prime}\right)\left(B^{\prime}-2 c^{\prime}-Q c^{\prime \prime}\right)}{\left(B^{\prime}-c^{\prime}\right)^{3}}
\end{aligned}
$$

Where we have omitted the subscript $i$ and all functions on the right hand side of (27) are evaluated at $Q(P)$.

Proof From (4) and (5) it follows that

$$
G_{i}(P)=\int_{0}^{Q_{i}(P)} B_{i}(q) d q-Q_{i}(P) c\left(Q_{i}(P)\right)
$$

Differentiating both sides of this identity with respect to $P$ and rearranging terms leads to (26). Differentiating (26) with respect to $P$ leads to:

$$
G^{\prime \prime}(P)=Q^{\prime \prime}(P)\left[P-c^{\prime}(Q(P)) Q^{\prime}(P)\right]+Q^{\prime}(P)\left[1-Q^{\prime}(P) c^{\prime}(Q(P))-Q(P) Q^{\prime}(P) c^{\prime \prime}(Q(P))\right] .
$$

Substituting $Q^{\prime}(P)$ and $Q^{\prime \prime}(P)$ by the expressions in Proposition A.1 leads to (27).

Lemma A.2 The social surplus, as a function of $Q$, satisfies:

$$
\begin{aligned}
\tilde{G}^{\prime}(Q) & =B(Q)-c(Q)-Q c^{\prime}(Q), \\
\tilde{G}^{\prime \prime}(Q) & =B^{\prime}(Q)-2 c^{\prime}(Q)-Q c^{\prime \prime}(Q)<0 .
\end{aligned}
$$

It follows that $\tilde{G}(Q)$ is strictly concave.

We also have the following relations between net social surplus as a function of $P$ and as a function of $Q:$

$$
\begin{aligned}
G(P) & =\tilde{G}(Q(P)) \\
G^{\prime}(P) & =\tilde{G}^{\prime}(Q(P)) Q^{\prime}(P), \\
G^{\prime \prime}(P) & =\tilde{G}^{\prime \prime}(Q(P))\left[Q^{\prime}(P)\right]^{2}+\tilde{G}^{\prime}(Q(P)) Q^{\prime \prime}(P) .
\end{aligned}
$$

Proof Expressions (28) and (29) follow directly from the definition of $\tilde{G}(Q)$. Expression (30) is by definition; expressions (31) and (32) follow directly from (30). 
Definition A.2 (Monopolist's toll) We denote the toll a monopolist charges in state $i$, that is the toll that maximizes $P Q_{i}(P)$, by $P_{i}^{M}$. We also denote $Q\left(P_{i}^{M}\right)$ by $Q_{i}^{M}$.

The following proposition shows that our assumptions - the non-trivial one being the concavity of the $B_{i}$ 's-ensure that demand is inelastic for all tolls below the monopolist's tolls, becoming more elastic as tolls increase.

Proposition A.2 (Properties of $\eta$ and $\mathcal{R}$ ) The price-elasticity $\eta_{i}$ satisfies:

$$
\begin{aligned}
\eta_{i}(0) & =0, \\
\eta_{i}^{\prime}(P) & <0, \\
\eta_{i}\left(P_{i}^{M}\right) & =-1 .
\end{aligned}
$$

Also, the (instantaneous) revenue function, $\mathcal{R}_{i}$, satisfies:

$$
\begin{aligned}
\mathcal{R}_{i}^{\prime}\left(P_{i}^{M}\right) & =0, \\
\mathcal{R}_{i}^{\prime}(P) & >0 \text { for } P<P_{i}^{M}, \\
\mathcal{R}_{i}^{\prime}(P) & <0 \text { for } P>P_{i}^{M} .
\end{aligned}
$$

Proof From (25) we have that:

$$
\eta(P)=\frac{P}{Q(P)\left[B^{\prime}(Q(P))-c^{\prime}(Q(P))\right]} .
$$

Evaluating this expression at $P=0$ proves (33).

Differentiating (37) with respect to $P$ we have:

$$
\eta^{\prime}(P)=\frac{Q\left[B^{\prime}-c^{\prime}\right]-P Q^{\prime}\left[B^{\prime}-c^{\prime}\right]+P Q^{\prime} Q\left[B^{\prime \prime}-c^{\prime \prime}\right]}{\left[Q\left(B^{\prime}-c^{\prime}\right)\right]^{2}} .
$$

Where the functions $Q, B, c$ and their derivatives are evaluated at $Q(P)$. Since our assumptions ensure that the three terms in the numerator have negative signs (with the first one being strictly negative), we conclude that $\eta^{\prime}(P)<0$.

Finally, (35) follows from the monopolist's first order condition:

$$
Q(P)+P Q^{\prime}(P)=0
$$

The properties for $\mathcal{R}$ follow from (34) and (35). 
Proposition A.3 (Unimodality of $G_{i}$ ) The net social surplus function, $G_{i}(P)$, is unimodal for $P \geq 0$.

Proof We have that $\tilde{G}^{\prime}(Q=0)=B(0)-c(0)>0$ (due to Assumption (2)). Since $\tilde{G}$ is concave (Lemma A.2), there are two possibilities:

1. $\tilde{G}^{\prime}(Q)>0$ for all $Q$. In this case it follows from (31) and (25) that $G^{\prime}(P)<0$ for all $P>0$. Hence $G(P)$ is unimodal attaining its maximum at $P=0$.

2. There exists a $Q^{*}>0$ such that $\tilde{G}$ is strictly increasing for $Q<Q^{*}$ and strictly decreasing for $Q>Q^{*}$, with $\tilde{G}^{\prime}\left(Q^{*}\right)=0 .{ }^{52}$

Let $P^{*}$ denote the unique $P$ such that $Q(P)=Q^{*}$. It then follows from (31) and (25) that $G(P)$ is strictly increasing for $P<P^{*}$ and strictly decreasing for $P>P^{*}$, attaining its maximum value at $P^{*}$.

Lemma A.3 The congestion toll, $P_{i}^{*}$, satisfies:

$$
\begin{aligned}
P_{i}^{*} & <P_{i}^{M}, \\
G_{i}^{\prime}\left(P_{i}^{*}\right) & =0 \\
P_{i}^{*} & =Q\left(P_{i}^{*}\right) c^{\prime}\left(Q\left(P_{i}^{*}\right)\right) .
\end{aligned}
$$

Proof To prove (38) we show that the number of trips chosen by the social planner, $Q^{*}$, is larger than the number of trips chosen by the monopolist, $Q^{M}{ }^{53}$ It then follows from (25) that $P^{*}<P^{M}$.

The monopolist chooses $Q^{M}$ as to maximize $[B(Q)-c(Q)] Q$, which leads to the first order condition:

$$
[B(Q)-c(Q)]-Q c^{\prime}(Q)+Q B^{\prime}(Q)=0
$$

Thus it follows from (28) that $\tilde{G}^{\prime}\left(Q^{M}\right)>0$, and since $\tilde{G}^{\prime \prime}<0$, we have that $Q^{M}<Q^{*}$.

To prove (39) we consider the two situations into which we broke up the proof of the preceding proposition. Equation (39) obviously holds in the second case. In the first case, where $P_{i}^{*}=0,{ }^{54}$ we have, from (26) and (33), that:

$$
G^{\prime}\left(P^{*}\right)=-Q(0) c^{\prime}(Q(0)) Q^{\prime}(0) \geq 0
$$

\footnotetext{
${ }^{52}$ We convene throughout this appendix that a function $f(x)$ is increasing when $f^{\prime}(x) \geq 0$ and strictly increasing when $f^{\prime}(x)>0$. A similar convention holds for what we call decreasing and strictly decreasing.

${ }^{53}$ As usual, we drop the subscript $i$.

${ }^{54}$ Strictly speaking in this case we have $G^{\prime}\left(0^{+}\right)=0$.
} 
Yet, from what we saw in the proof of Proposition A.3, in this case $G^{\prime}(P)<0$ for all $P>0$. From continuity of $G^{\prime}(P)$ it follows that $G^{\prime}(0)=G^{\prime}\left(P_{i}^{*}\right)=0$.

Corollary A.1 If $P_{i}^{*}=0$ then $c(Q)$ is constant.

Proof From Lemma A.3 we have that $G^{\prime}\left(P^{*}\right)=0$ implies that either $Q^{\prime}(0)=0$ or $c^{\prime}(Q(0))=0$. The former cannot hold due to Proposition A.1. Thus $c^{\prime}(Q(0))=0$, and since $c(Q)$ is convex and $Q(0) \geq Q(P)$, it follows that $c^{\prime}(Q) \leq 0$. Since we assumed that $c^{\prime}(Q) \geq 0$, it follows that $c^{\prime}(Q) \equiv 0$ and thus that $c(Q)$ is constant.

Lemma A.4 Define

$$
J(P) \equiv B(Q(P))-c(Q(P))-Q(P) c^{\prime}(Q(P))
$$

Then:

$$
\begin{aligned}
& J\left(P^{*}\right)=0, \\
& J^{\prime}(P) \geq 1 \text { for all } P>0, \\
& J(P)>0 \text { for all } P>P^{*} .
\end{aligned}
$$

Proof Expression (41) follows from (24) and (40).

It follows from (41) that:

$$
J^{\prime}(P)=1-Q^{\prime}(P) c^{\prime}(Q(P))-Q(P) Q^{\prime}(P) c^{\prime \prime}(Q(P))
$$

Then (42) follows from the fact that both $Q^{\prime} c^{\prime}$ and $Q Q^{\prime} c^{\prime \prime}$ are negative.

Finally, (43) is a direct consequence of (41) and (42).

Proposition A.4 (Concavity of the net social surplus) The function $G_{i}(P)$ is strictly concave for $P \geq P_{i}^{*}$.

Proof Since $B^{\prime}-c^{\prime}<0, B^{\prime}-2 c^{\prime}-Q c^{\prime \prime}<0$, and $B^{\prime \prime}-c^{\prime \prime} \leq 0$, it follows from (27) that a sufficient condition for $G^{\prime \prime}(P)<0$ is that $B-c-Q c^{\prime} \geq 0$, which holds due to Lemma A.4.

Example A.1 Consider $B(Q)=B_{0}-B_{2} Q^{2}$, for $Q \leq\left(B_{0} / B_{2}\right)^{1 / 2}$ and $B(Q)=0$ elsewhere. Also consider $c(Q)=C_{0}+C_{2} Q^{2}$ and assume that the constants $B_{0}, B_{2}, C_{0}$ and $C_{2}$ are positive with $B_{0}>C_{0}$. It then follows from (2) that the demand function is given by:

$$
Q(P)= \begin{cases}\sqrt{\frac{B_{0}-C_{0}-P}{B_{2}+C_{2}}} & \text { if } P \leq B_{0}-C_{0} \\ 0 & \text { otherwise }\end{cases}
$$


Hence, for $P \leq B_{0}-C_{0}$ :

$$
\begin{aligned}
Q^{\prime}(P) & =-\frac{1}{\sqrt{\left(B_{2}+C_{2}\right)\left(B_{0}-C_{0}-P\right)}}<0, \\
\eta(P) & =-\frac{P}{2\left(B_{0}-C_{0}-P\right)} .
\end{aligned}
$$

Consistent with Proposition A.2, $\eta(0)=0$ and $\eta^{\prime}(P)<0$. We also have that $\eta\left(P^{M}\right)=-1$ leads to:

$$
P^{M}=\frac{2}{3}\left(B_{0}-C_{0}\right)
$$

From (26), (44) and (45) we have that:

$$
G^{\prime}(P)=\frac{2 C_{2}\left(B_{0}-C_{0}\right)-\left(B_{2}+3 C_{2}\right) P}{2\left(B_{2}+C_{2}\right)^{3 / 2} \sqrt{B_{0}-C_{0}-P}}
$$

From the preceding expression and (39) it follows that:

$$
P^{*}=\frac{2 C_{2}\left(B_{0}-C_{0}\right)}{3 C_{2}+B_{2}}=\frac{2\left(B_{0}-C_{0}\right)}{3+\frac{B_{2}}{C_{2}}},
$$

which implies that, as implied by (38), $P^{*}<P^{M}$. Finally we have that from (27):

$$
G^{\prime \prime}(P)=-\frac{B_{0}-C_{0}+\left(B_{2}+3 C_{2}\right) Q^{2}}{4\left(B_{2}+C_{2}\right)^{2} Q^{3}}<0
$$

\section{B Planner's solution}

In this appendix we characterize the planner's solution in the commitment case.

We denote by $I_{\max }^{c}$ and $I_{\max }^{n c}$, the highest construction cost for a given road consistent with firms' participation constraint, respectively in the case with and without commitment. Thus $I_{\max }^{c}$ is the unique $I$ satisfying

$$
\sum_{i} \pi_{i} u\left(\mathrm{PVR}_{i}^{M}-I\right)=u(0)
$$

while

$$
I_{\max }^{n c}=\min _{i} \operatorname{PVR}_{i}^{M}
$$

It is obvious that $I_{\max }^{c} \geq I_{\max }^{n c}$, with equality only in exceptional cases. In what follows we assume that $I \leq I_{\max }^{c}$ in the case with commitment and $I \leq I_{\max }^{n c}$ in the case without commitment. 
Lemma B.1 The functions $H_{i}(P)$ and $v_{i}(P, L)$ satisfy:

$$
\begin{aligned}
H_{i}\left(P_{i}^{*}\right) & =1, \\
H_{i}\left(P_{i}^{M}\right) & =0, \\
H_{i}^{\prime}(P) & <0, \quad \text { for } P_{i}^{*} \leq P<P_{i}^{M}, \\
H_{i}(P) & =\frac{1+\eta_{i}(P)}{1+c^{\prime}\left(Q_{i}(P)\right) Q_{i}^{\prime}(P)}, \\
\frac{\partial v_{i}}{\partial P}(P, L) & <0, \quad \text { for } P_{i}^{*} \leq P \leq P_{i}^{M}, \\
\frac{\partial v_{i}}{\partial L}(P, L) & >0, \quad \text { for } 0 \leq L \leq 1 .
\end{aligned}
$$

Proof Identity (46) follows from (39); identity (47) from (35).

Expression (48) follows from the fact that $Q(P)(1+\eta(P))$ is positive and strictly decreasing in $P$ for $P \leq$ $P^{M}$ (see Proposition A.2) and $G^{\prime}(P)$ is negative and strictly decreasing in $P$ for $P>P^{*}$ (see Proposition A.4). Expression (49) follows from (26).

That $v(P, L)$ is strictly decreasing in the first argument follows from the fact that it is the product of two positive, strictly decreasing functions of $P .{ }^{55}$ Finally, $v(P, L)$ is strictly increasing in its second argument because $\operatorname{PVR}_{i}(L)$ is decreasing in $L$ and $u$ concave.

Lemma B.2 Fix $s \in\{1,2, \ldots, n\}$ and define:

$$
\begin{aligned}
& P_{k}(s)=P_{k}^{*}, \quad \text { for } k=s, s+1, \ldots, n ; \\
& L_{k}(s)=1-\frac{P V R_{s}^{*}}{P V R_{k}^{*}}, \quad \text { for } k=s, s+1, \ldots, n ; \\
& L_{k}(s)=0, \quad \text { for } k=1,2, \ldots, s-1 .
\end{aligned}
$$

Denote by $P_{k}(s), k=1,2, \ldots, s-1$, the unique $P$ that satisfies: ${ }^{56}$

$$
v_{k}(P, 0)=v_{s}\left(P_{s}^{*}, 0\right)
$$

Then there exists a unique value of $I$, which we denote by $I(s)$, for which the tolls and franchise lengths defined above correspond to the social planner's choice when commitment is possible. Furthermore, I(s) is increasing in $s$.

\footnotetext{
${ }^{55}$ That $u^{\prime}\left(\frac{P Q_{i}(P)}{r}(1-L)-I\right)$ is strictly decreasing in $P$ follows from Proposition A.2.

${ }^{56}$ The existence of a unique solution follows from the fact that $v_{k}(P, 0)$ is strictly decreasing in $P$ (see $(50)$ ), with $v_{k}\left(P_{k}^{*}, 0\right) \geq$ $v_{k}\left(P_{s}^{*}, 0\right)\left(\right.$ since $\left.\mathrm{PVR}_{k}^{*} \leq \mathrm{PVR}_{s}^{*}\right)$ and $v_{k}\left(P_{k}^{M}, 0\right)=0<v_{k}\left(P_{s}^{*}, 0\right)$ (due to $\left.(47)\right)$.
} 
Proof The tolls and franchise lengths satisfy the first order conditions specified in (18) by construction. Denote the present value of the revenue the franchise holder receives in state $i$ by $\operatorname{PVR}_{i}(s)$. To complete the proof we must show that there exists $I=I(s)$ such that:

$$
\sum_{i=1}^{n} \pi_{i} u\left(\operatorname{PVR}_{i}(s)-I\right)=u(0)
$$

This follows from the fact that the left hand side of the preceding equation is (a) strictly decreasing in $I$; (b) larger than $u(0)$ when evaluated at $I=0$; and (c) smaller than $u(0)$ when evaluated at $I$ larger than $\max _{i} \operatorname{PVR}_{i}(s)$.

To show that $I(s)$ increases with $s$, we note that by construction the $P_{i}(s)$ 's are increasing in $s$, which implies that the $\operatorname{PVR}_{i}(s)$ 's also increase with $s$ (from (36)) and therefore, due to (51), so do the $I(s)$.

Definition B.1 Lemma B.2 shows that there exists a unique value of I for which the social planner's solution sets an indefinite franchise in state $s$ with toll equal to $P_{s}^{*}$. The corresponding tolls, franchise lengths and franchise revenues are denoted by $P_{i}(s), T_{i}(s)$ and $P V R_{i}(s)$, respectively. The corresponding value of $I$ is denoted by $I(s)$.

Theorem B.1 (Characterization when $I \leq I(1)$ ) Assume $I \leq I(1) .{ }^{57}$ Then the unique solution to the planner's problem is obtained setting $P_{i}=P_{i}^{*}$ and $L_{i}(I)=1-\left(I / \mathrm{PVR}_{i}^{*}\right)$.

Proof It follows from the definition of $P_{i}$ and $L_{i}$ that the franchise holder's revenue in all states of demand is I. Since we also have non distortionary tolls, the $P_{i}$ 's and $L_{i}$ 's satisfy the first order conditions (18). Finally, the firm's participation constraint is (trivially) satisfied.

Theorem B.2 (Characterization when $I>I(n)$ ) Assume $I>I(n),{ }^{58}$ For $0 \leq \alpha \leq u^{\prime}\left(P V R_{n}^{*}-I\right)$ define $P_{i}(\alpha)$ as the unique (due to (50)) solution to:

$$
v_{i}\left(P_{i}(\alpha), 0\right)=\alpha, \quad \text { for } i=1, \ldots, n,
$$

and set the franchise lengths at infinity for all states of demand:

$$
L_{i}(\alpha)=0, \quad \text { for } i=1, \ldots, n .
$$

\footnotetext{
${ }^{57}$ This is the case where the road is relatively cheap to build compared with expected revenues, so that it can be financed charging the congestion toll in every state of demand.

${ }^{58}$ This means that the road is relatively expensive compared with the revenue it can generate. As usual, the firm's participation constraint holds, that is:

$$
\sum_{i} \pi_{i} u\left(\mathrm{PVR}_{i}^{M}-I\right) \geq u(0)
$$
}

Where $\mathrm{PVR}_{i}^{M}$ denotes the firm's revenue if it charge's the monopoly toll in an indefinite franchise in state $i$. 
Then there exists a unique value of $\alpha$ such that the tolls $P_{i}(\alpha)$ and franchise lengths $L_{i}(\alpha) ; i=1, \ldots, n$, fully characterize the planner's solution. The corresponding value of $\alpha$ is the unique solution to:

$$
\sum_{i} \pi_{i} u\left(P V R_{i}(\alpha)-I\right)=u(0)
$$

Where $P V R_{i}(\alpha)=P_{i}(\alpha) Q_{i}\left(P_{i}(\alpha)\right) / r$.

Proof By construction the $\left(P_{i}(\alpha), L_{i}(\alpha)\right)$ 's satisfy the first order conditions (18). From (52) and (50) it follows that $P_{i}$, and therefore $\mathrm{PVR}_{i}$ is strictly decreasing in $\alpha$. Denoting the left hand side of (53) by $S(\alpha)$ it then follows that $S$ is continuous and strictly decreasing in $\alpha$. We also have, due to (47):

$$
S(0)=\sum_{i} \pi_{i} u\left(\mathrm{PVR}_{i}^{M}-I\right) \geq u(0)
$$

And, with the definition of $I(n)$ and $\operatorname{PVR}_{i}(n)$ given in Definition B.1:

$$
\begin{aligned}
S\left(u^{\prime}\left(\mathrm{PVR}_{n}^{*}-I\right)\right) & =\sum_{i} \pi_{i} u\left(\mathrm{PVR}_{i}(n)-I\right) \\
& <\sum_{i} \pi_{i} u\left(\mathrm{PVR}_{i}(n)-I(n)\right) \\
& =u(0) .
\end{aligned}
$$

Where the strict inequality follows from the assumption that $I>I(n)$. Existence and uniqueness of $\alpha$ satisfying (53) now follow.

Theorem B.3 (Characterization when $I(1)<I \leq I(n)$ ) Assume that $I(s) \leq I \leq I(s+1)$ for $s \in\{1,2, \ldots, n-$ $1\} .{ }^{59}$ Given $\gamma \in[0,1]$ define:

$$
\begin{aligned}
& P_{i}(\gamma)=P_{i}^{*}, \quad \text { for } i=s+1, \ldots, n \\
& L_{i}(\gamma)=1-\frac{P V R_{s+1}^{*}}{P V R_{i}^{*}}(1-\gamma), \text { for } i=s+1, \ldots, n
\end{aligned}
$$

For $i \leq s$ set $L_{i}(\gamma)=0$ and define $P_{i}(\gamma)$ as the unique $P$ satisfying: ${ }^{60}$

$$
v_{i}(P, 0)=u^{\prime}\left(P V R_{i}(\gamma)-I\right)
$$

\footnotetext{
${ }^{59}$ That a unique integer $s$ between 1 and $n-1$ satisfying these inequalities exists follows from the fact that $I(s)$ is increasing in $s$, see Lemma B.2.

${ }^{60}$ The argument explaining why such a $P$ is uniquely determined is the same as that in footnote 56.
} 
Where

$$
P V R_{i}(\gamma)=\frac{\left.P_{i}(\gamma) Q_{i}\left(P_{i}(\gamma)\right)\right)}{r}\left(1-L_{i}(\gamma)\right)
$$

Then the unique solution to the planner's problem with commitment is the set of $P_{i}(\gamma)$ 's and $L_{i}(\gamma)$ 's corresponding to the unique value of $\gamma\left(\right.$ in $\left.\left[0,1-\left(\mathrm{PVR}_{s}^{*} / \mathrm{PVR}_{s+1}^{*}\right)\right]\right)$ that satisfies:

$$
S(\gamma) \equiv \sum_{i} \pi_{i} u\left(P V R_{i}(\gamma)-I\right)=u(0)
$$

Proof We first note that the assumption $I(s) \leq I \leq I(s+1)$ implies that:

$$
\begin{aligned}
\sum_{i} \pi_{i} u\left(\mathrm{PVR}_{i}(s)-I\right) & \leq u(0), \\
\sum_{i} \pi_{i} u\left(\mathrm{PVR}_{i}(s+1)-I\right) & \geq u(0) .
\end{aligned}
$$

By construction the $\left(P_{i}(\gamma), L_{i}(\gamma)\right)$ 's satisfy (18). Thus all that remains to be shown is that there exists a unique $\gamma$ that satisfies $S(\gamma)=u(0)$.

We have that $\operatorname{PVR}_{i}(\gamma)$ is strictly decreasing in $\gamma,{ }^{61}$ and therefore $S^{\prime}(\gamma)<0$. Furthermore, from the definition of the $\operatorname{PVR}(s)$ 's in Definition B.1, and (55) and (56) it follows that:

$$
\begin{aligned}
S(0) & =\sum_{i} \pi_{i} u\left(\mathrm{PVR}_{i}(s+1)-I\right) \geq u(0), \\
S\left(1-\frac{\mathrm{PVR}_{s}^{*}}{\mathrm{PVR}_{s+1}^{*}}\right) & =\sum_{i} \pi_{i} u\left(\mathrm{PVR}_{i}(s)-I\right) \leq u(0) .
\end{aligned}
$$

Thus the characterization of the planner's solution holds.

Definition B.2 For every $i$ define $\widetilde{P}_{i}$ as the unique toll that satisfies $P Q_{i}(P)=r I$.

\section{Corollary B.1 (Comparison of solutions with and without commitment)}

(a) When $I \leq I(1)$ the planner's solution with and without commitment are the same.

(b) When $I>I(1)$, the planner's solutions with and without commitment are the same if and only if $H_{i}\left(\widetilde{P}_{i}\right)$ does not vary with $i$.

Proof Since in the case without commitment the franchise holder's revenue is the same in all states of demand, (18) implies that the $H_{i}\left(\widetilde{P}_{i}\right)$ 's do not vary with $i$ when both solutions coincide. Statements (a) and (b) now follow directly.

\footnotetext{
${ }^{61}$ The argument for the case where $i \geq s+1$ may be found in the proof of Theorem B.1; the one for the case where $i \leq s$ in the proof of Theorem B.2.
} 
In most cases (generically) we have that the planner's solutions without and with commitment are the same only when $I \leq I(1)$, that is, when the road is sufficiently cheap to build (relative to expected demand) so that in all states of demand it can be financed setting the congestion toll. The only interesting exception we can think of is when there is no congestion $\left(c^{\prime}(Q) \equiv 0\right)$ and demand in different states of nature only differs by a multiplicative constant:

$$
Q_{i}(P)=z_{i} B^{-1}(P)
$$

Corollary B.2 Denote by $\operatorname{PVR}_{k}^{O}(I)$ the present value of revenue received in state of demand $k$ under the optimal contract with commitment when construction costs are equal to I. Then $\mathrm{PVR}_{k}^{O}$ is strictly increasing in $I$.

Proof The intuition behind this result is the following. The franchise holder's revenue in state $k$ increases with $I$ either because the franchise length increases $(I<I(k))$ or because the optimal toll increases $(I>I(k))$.

The formal proof considers three ranges for $I$ :

1. $I \leq I(1)$.

It follows from Theorem B. 1 that in this case $\mathrm{PVR}_{k}^{O}$ is equal to $I$ (and therefore strictly increasing in $I)$.

2. $I \geq I(n)$.

With the notation introduced in the proof of Theorem B.2 we have that (52) and (50) imply that $\operatorname{PVR}_{k}(\alpha)$ is strictly decreasing in $\alpha$. It then follows from the firm's participation constraint

$$
\sum_{i} \pi_{i} u\left(\operatorname{PVR}_{i}(\alpha(I))-I\right)=u(0)
$$

that $\alpha$ is strictly decreasing in $I$. Thus $\operatorname{PVR}_{k}^{O}$ is strictly increasing in $I$.

3. $I(s) \leq I \leq I(s+1)$.

With the notation introduced in the proof of Theorem B.3 we have that $\operatorname{PVR}_{k}(\gamma)$ is strictly decreasing in $\gamma$. It then follows from

$$
\sum_{i} \pi_{i} u\left(\operatorname{PVR}_{i}(\gamma(I))-I\right)=u(0)
$$

that $\gamma$ is strictly decreasing in $I$. Thus $\operatorname{PVR}_{k}^{O}$ is strictly increasing in $I$. 


\section{Sub-optimality of fixed-term auctions}

Proposition C.1 (Suboptimality of fixed-term auctions) A fixed term auction is optimal if and only if $\mathrm{PVR}_{i}^{*}$ is the same in all states of demand, and this common value is larger than I. Thus generically a fixed term franchise is suboptimal.

Proof We present the proof for the case with commitment. The case without commitment is analogous.

A necessary condition for a fixed term franchise to be optimal is that, in the planner's solution, the franchise length be the same in all states of demand. From Proposition 3.6 it follows that this holds in two situations. First, when $\mathrm{PVR}_{i}^{*}$ is the same in all states and this common value is larger than $I$. In this case the optimal franchise length is the same across states of demand and finite. The planner sets $P_{i}=P_{i}^{*}$ and the winning bid attains the planner's solution.

The second case where the franchise length is the same in all states of demand is when it extends indefinitely. Yet in this case the planner cannot infer from the winning bid which is the value of $I$ and therefore is unable to set the optimal tolls after the winning bid is revealed. It follows that a fixed term franchise is optimal only in the first case.

\section{A model of a risk averse firm}

In this appendix we present a model that rationalizes a paradoxical feature of the financing of highway franchises, namely that entrepreneurs seem to be unable to diversify risks.

Consider the case of the owner of a construction firm whose profits are $s$, a random variable with cumulative distribution function $F\left(\cdot ; \bar{s}, \sigma_{s}^{2}\right)$, where $\bar{s}$ and $\sigma_{s}^{2}$ denote the corresponding mean and variance. The entrepreneur is the sole owner of the firm and is risk averse, so that his expected utility is

$$
W=\int u(y) d G(y)
$$

Where $u$ is strictly increasing and strictly concave, $y$ denotes the entrepreneur's net income and $G(y)$ the corresponding cumulative distribution function.

In general the entrepreneur will be willing to shed some risk. Consider a risk neutral investor who is considering whether to invest in this project. She knows that $s$ is a private signal and that the entrepreneur, either as a member of a partnership or as the manager of a company fully owned by the investor, always declares that company profits are zero if not monitored. ${ }^{62,63}$

\footnotetext{
${ }^{62}$ The investor leaves the entrepreneur as a manager due to his superior specialized knowledge.

${ }^{63}$ This strategy is weakly dominant in the subgame after the investment is committed.
} 
The investor can always verify, i.e., make claims to a fraction $\alpha(e)$ of total profits at a cost $e$ of effort in monetary terms. As usual, $\alpha(e) \in[0,1], \alpha^{\prime}>0, \alpha^{\prime \prime}<0$. For simplicity, we assume that the price $p$ of the company set by the entrepreneur does not depend on the share that the investor buys. ${ }^{64}$ The expected profits for the investor of buying a share $\beta$ of the company is

$$
\Pi(e, \beta)=\beta \alpha(e) \bar{s}-e-\beta p
$$

Since the investor is risk neutral, she maximizes expected utility as a function of effort and the share of the company she buys. As we assumed that $p$ does not depend on $\beta$, the maximization problem leads to $\beta=1$ if the investor buys at all, and hence effort satisfies

$$
\alpha^{\prime}(e) \bar{s}=1
$$

It follows that the maximum price $p$ at which the investor is willing to buy the company is the price that solves

$$
\bar{s} \alpha\left(e^{*}\right)-e^{*}-p=0
$$

Where $e^{*}$ is the profit maximizing level of effort (characterized by (57)).

Consider now the utility of the entrepreneur in the two polar cases. If he asks for a price such that the investor does not buy into the firm (he holds the firm) his welfare is given by

$$
W_{h}=\int u(s) d F(s)
$$

Whereas if the investor buys out the firm and leaves the entrepreneur as the manager, the manager's welfare from selling is

$$
\begin{aligned}
W_{s} & =\int u\left(\left(1-\alpha^{*}\right) s+p\right) d F(s) \\
& =\int u\left(s+\alpha^{*}(\bar{s}-s)-e^{*}\right) d F(s)
\end{aligned}
$$

Where we used (58) in the last step, $\alpha^{*} \equiv \alpha\left(e^{*}\right)$, and we have assumed that the manager appropriates the non-verifiable profits. Next, consider two extreme cases for the entrepreneur's attitude toward risk. If he is risk neutral, he has a cost advantage over the investor, since he does not have to incur the verification cost and he gets the full profits from the project. In this case he does not sell the firm. On the other hand, if he is infinitely risk averse, he maximizes the lowest expected utility, which occurs when he sells the firm. It

\footnotetext{
${ }^{64}$ Even though the derivation is more complex, the result that follows continues holding if this assumption is relaxed.
} 
follows that as the entrepreneur's risk aversion grows, there is a positive degree of risk aversion at which he switches from keeping to selling the project. In what follows, we prove this intuition.

A second order Taylor approximation for $u$ around $\bar{s}$ leads from (60) to

$$
\begin{aligned}
W_{s} & \simeq \int\left[u(\bar{s})+\left\{\left(1-\alpha^{*}\right)(s-\bar{s})-e^{*}\right\} u^{\prime}(\bar{s})+\frac{1}{2}\left\{\left(1-\alpha^{*}\right)(s-\bar{s})-e^{*}\right\}^{2} u^{\prime \prime}(\bar{s})\right] d F(s) \\
& =u(\bar{s})-e^{*} u^{\prime}(\bar{s})+\frac{1}{2}\left(1-\alpha^{*}\right)^{2} \sigma_{s}^{2} u^{\prime \prime}(\bar{s})+\frac{1}{2} e^{* 2} u^{\prime \prime}(\bar{s}),
\end{aligned}
$$

and from (59) to

$$
W_{h} \simeq u(\bar{s})+\frac{1}{2} \sigma_{s}^{2} u^{\prime \prime}(\bar{s})
$$

Taking the difference, we have

$$
W_{s}-W_{h} \simeq \frac{1}{2}\left[\left(\alpha^{* 2}-2 \alpha^{*}\right) \sigma_{s}^{2}+e^{* 2}\right] u^{\prime \prime}(\bar{s})-e^{*} u^{\prime}(\bar{s})
$$

Denoting by $\rho=-u^{\prime \prime}(\bar{s}) \bar{s} / u^{\prime}(\bar{s})$ the entrepreneur's coefficient of relative risk aversion evaluated at $\bar{s}$, we have that $(61)$ is equivalent to

$$
W_{s}-W_{h} \simeq \frac{u^{\prime}(\bar{s})}{\bar{s}}\left[\frac{1}{2}\left\{\alpha^{*}\left(2-\alpha^{*}\right) \sigma_{s}^{2}-e^{* 2}\right\} \rho-e^{*} \bar{s}\right]
$$

Hence, given that the investor's optimal choice of effort $e^{*}$ is independent of the entrepreneur's degree of relative risk aversion (see (57)), we have the following proposition:

Proposition D.1 Suppose $\alpha^{*}\left(2-\alpha^{*}\right) \sigma_{s}^{2}>e^{* 2},{ }^{65}$ then there exists $\rho^{*}>0$ such that for $\rho<\rho^{*}$, the entrepreneur does not sell the firm. When $\rho>\rho^{*}$, the firm is sold.

The relevant part of the proposition is that for all $\rho \in\left(0, \rho^{*}\right)$ the entrepreneur prefers not to sell and must, therefore, assume all the risk of the company. For these values of $\rho$ the behavior of the firm is that of the risk averse entrepreneur.

\footnotetext{
${ }^{65}$ Other things equal, this holds if $\sigma_{s}^{2}$ is sufficiently large.
} 